Portland State University

PDXScholar

1971

\title{
Interorganizational Coalitional Decision-making: an Exploratory Investigation
}

Dennis Brian Keenan

Portland State University

Follow this and additional works at: https://pdxscholar.library.pdx.edu/open_access_etds

Part of the Social Work Commons

Let us know how access to this document benefits you.

\section{Recommended Citation}

Keenan, Dennis Brian, "Interorganizational Coalitional Decision-making: an Exploratory Investigation" (1971). Dissertations and Theses. Paper 1682.

https://doi.org/10.15760/etd.1681

This Thesis is brought to you for free and open access. It has been accepted for inclusion in Dissertations and Theses by an authorized administrator of PDXScholar. Please contact us if we can make this document more accessible: pdxscholar@pdx.edu. 


\section{(INTERORGANIZATIONAL COALITICNAL.}

DECISION-MAKING): AN EXPLORATORY INVESTIGATION.

$$
\text { by }
$$

DENNIS BRIAN KEENAN

A practicum report submitted in partial fulfillment of the requirements for the degree of

MISTER OF

SCCIAL WCRK

Portland State University

1972 ,

Approved by

- Gdrald A. FreYT

Sumner H. Sharpo 
Th1s study 18 one of four exploratory studies concerned with coalitions of organizations that are formed to plan and develop social welfare programs within the local community. Although each study was conducted independentily, taken together, their major purpose was to develop some insights and knowledge into the behavior of organizations and the ways in which they interact as they work together to develop community programs. They are then, exploratory studies of interorganizationel behavior.

Each of the studies had a different focus. One study attempted to identify the present areas of agreoment and disagreement regarding interorganizational behavior by systematically reviewing the literature over the past ten years. Another focused on the stages of development of the coalition, attempting to determine if organizational coalitions seemed to follow simllar developmental patterns as has been reported in the literature on small groups. Another focused on the decision-making patterns in the coalitions by first reviewing the literature and constructing a decisionmaking model and then "testing" the model against a set of case histories. The final study, following a grounded theory approach, simply tried to 1dentify a set of common variables or analytical categories which seemed to be present. in a number of coalitions. Al- 
though each of these exploratory studies was conducted Independently with a different emphasis and analyt1cal focus, they each utilized the same data - a set. of case histories of coalitions. Consequentiy, each of the studies utilized a common set of data but viewed the data from quite different analytical perspectives.

The particular focus of this study is upon the decision-making patterns in coalitions. In reviewing the literature, formulating an analytical model, and applying the same to the casestudies, two princlpal areas of concern are focused upon: decision-makine power analysis and decision-making process analysis. The Iiterature provided essentially no material on coalitional decision-making as such. However, the broader category of organizational decision-makirg behavior did contain conceptual and theoretical notions which were applicable to coalitional decisionmaking by means of inference and extrapolation into hypothetical propositions around power and process 1ssues. These 2 dimensions were then explored through the use of these hypothetical propositions by "test1ng" them ageinst the case history data. The results were then assessed with subsequent modifications where conceptual weaknesses were evident. A final chapter. was included to relate what the researcher learned, what other researchere might learn from that experience, 
and what Soclal Work could learn from the study about. the area of coalitional decision-making.

There 18 nothing new about the concept of a coalition of organizations. Organizational coalitions have been formed and reformed ever since man began working through organizational structures. They are common, everyday occurrences, yet surprisingly ilttie 1s known about them since much of the theoretical work has focused on coalitions of individuals or smali! Groups or or the alliances and coalitions of political groups and nations. Surprisingly little work has been: done specifically on organizational coalitions..

A coalition of organizations is an interorganizational structure. That is, a structure in which two or more organizations deliberately relate their behavior to each other as when several organizations jointIy agree to plan some new program in the community. They are also unique structures in: that each of the organizations maintains 1 ts own autonomy, but for a period of time they work together around some common 1ssue or mutual problem.

Coalitions, in contrast to other types of interorganizational structures such as counc1ls or fed-erations, tend to be ad hoc and issue-oriented structures. That 18,. there is 11ttle permanence to the Btructure. A group of organizations joim together around an 18sue, meet for a period of time, and simply 
disband or dissolve once the issue is resolved. They are rather fluid and amorphous structures but they do represent one of the ways that organizations cooperate with each other.

Within recent years the coalition has been viewed as a possible means to coordinate disparate programs within the community. The office of Economic Cpportunity and the United Way of America have jointly sponsored a project to examine the use of coalition in the planning process. To some degree then, the coalition seems to be an increasingly 1mportant structure and one that needs to be fully understood by the planner if it 18 to be effectively ut1lized.

Consequently, an increased knowledge of organ1zational behavior, expecially on the relationship between organizations, would not only ald the plan- ner in his dally tasks but at the same time contribute to the IImited knowled 8 of interorganizational behavior. 


\section{CHAPTER 1 \\ Review Cf The Litereture}

The 11terature reviewed was concemed with two primary areas of analysis of decision-making: power and process. I. Power Analysis of Decision-Making

While few of the works reviewed dealt primarily with interorganizational coalitions, most of them in some way were concerned with the issue of power and influence in the decisionmaklng process, which often secondarily related to the issue of coalitions. These writings focused on matters of theory, structure, and exchange.

\section{A. Theoretical:}

Because of the general recognition of the significance of power and influence in decision-making, a review of methods of power analysis and theory was regarded to be helpful. Consequently, the perspectives of four scholars of power and influence analysis will be briefly summarized.

Interorganizational coalitions, being an informal, temporary coalescence of members from separate formal organizations with their own respective interests, the relevance of power theory is evident. Terry Clark summarizes the three analytiaal models which are most broadly used to ascertain the power structure of decision-making: "positional," "reputational," and "dec1sional." The "positional method" attempts to discover community "leaders" through complilng a list of the occupants of the top positions in significant "community organizations." 1

The "reputational method" gathers a panel of community mem- 
bers and asks them about the leaders in the community; and, from th1s, a list of leaders is developed. A variation of this method is the "1ssue-specific reputational method." It asks informants: to score or rank individual community leaders with regard to their power in "specific issue areas." 2

The "decisional method" follows the history of specific dec1sions or issue areas and seeks to identify the significant persons who were involved in the actual decisions and those whose recommendations were accepted. It does not deal with indirect influence and value blas influences. The decislonal method can be refined further by taking into account the impact of past decisions upon current power structures. 3

Three writers, Banfield, Dahl, and Polsby attempt to devise theoretical models of power and influence analysis in more operational terms. The first of the authors, Edward Banfleld, defines "Influence" as the "ability to get others to act, think, or feel as one intends." Viewed within a social or political context of "concerted" decision-making and activity, Banfield asserts that "Any cooperative activity - and so any organization, formal or informal, ephemeral or lasting - may be viewed as a system of influence." 4 To obtain an overview of relevant material from Banfield, the study will examine his analytical model for studying influence and secondly, his propositions about. the operations of influence.

The basic conceptual scheme used by Banfield to analyze "Influence" in his casestudies was constructed around four principal questions:: 
1. "Who has influence and who is subject to 1 t?"

2. "How does influence work?"

3. "What are the terms upon which influence is expended?"

4. "How is action concerted by influence?" 5

From his analysis of casestudies through the use of the above model, Banfield derived certain basic propositions about the processes of influence. Among others, these included:

1. The wider the distribution of authority, the larger the stock of power that is required if proposals are to be adopted.

2. As the number of autonomous actors in a situation increases, the probability of adoptions decresses.

3. As the number of autonomous actors increases, control tends to become less structured.

4. The more power an actor has, the less he will be affected by uncertainty in his efforts to secure control.

5. The more kinds of power an actor has, the greater the probabllity that he can secure control in a given case.

6. The probability of adoptions (and the probability that there w1ll not be much compromise) tends to increase as the correspondence improves between the kinds of power that powerholders have at their disposal and the kinds to which actors will respond.

7. The "economies of scale" that arise from ccntrolling a - tructure and from having a large and varied "inventory" of power give a cumulative advantage to certain actors and thus may lead to structural centralization.

8. In situations where there is a shortage of power in relation to profitable opportunities for its exercise (i.e., a shortage of investment capital), there will be a tendency to kill some proposals and to compromise others in order to increase the supply of power.

9. When public-regarding power does not suffice to meet the needs of a system (either because there is not enough of 1t or because those over whom control is to be established will not respond to (t) there will be a tendency to employ private-regarding power in 1 ts place. 6

The second writer,. Robert Dahl also proposes a model for analyzing power and its use. For Dahl, power 18 the capacity of one actor to influence the other to the extent that the second does something he would not do otherwise. Dahl then delineates certain propositions about influence. He maintains that there are three essential concepts or propositions which serve to ex- 
plain why some actors have more influence than others, as well as, demonstrating the difference between "potential" and "actual Influence:

1. Some actors have more political resources at their disposal than others. $\mathrm{Cr}$

2. Given the resources at their disposal, some actors use more of them to gain political influence. Cr

3. Given the resources at their disposal some actors use them more skilifuliy or effectively than others do. 7

He also asserts the existence of two basic types of inPluence: "coercive influence" (negative, positive; punishment, reward) and "rellable influence" (high probabllity of compliance). 8

A third writer, Nelson W. Polsby, is concerned with scrutinizing the existing power analysis approaches in terms of the questionable validity of their methodology. In his analysis, he defines power as "the capacity of one actor to do something affecting another actor, which changes the probable pattern of specifled future events." 9 There are three basic guestions in the power analysis theories according to Polsby: "(1) the problem of identifying and characterizing participants in decisionmaking, (2) the problem of determining who gains and who loses from outcomes of decisions, (3) the problem of discovering what. makes for successful participation in decision-making." 10 Polsby assumes a pluralist notion of society and community power. From studies utilizing the above analytical framework for Investigation, Polsby has drawn some general propositions about power in decision-making. With respect to "who governs," he maintains that decision-making participants are usually specialized in certain "18sue areas." He holds that this limits appli- 
cability of an elitist model of power. In the area of "who gains" and "who loses," Polsby cautions the universal1ty and reliablilty of these questions, because many value outcomes of community decisions are frequently distributed in "unintended, unanticlpated ways" and the powerful often intentionally "distribute. values to the nonpowerful." So, whlle useful for analyzing value distribution, the above inquiry is not useful in disclosing power atructures. The 1ssue of "who succeeds" is approached by the use of three indices: "when an actor initiates some commun-ity policy, meets with no opposition, and it is enacted; when an actor prevents the policy of some other actor from being enacted; and when an actor inliates a policy, meets with oppositicn, and the policy is enacted." 11

One of the usual methods whereby actors assure their success for Polsby is through coalition formation. He has developed certain hypotheses about these coalitions. They are established by actors to increase their resources to pursue their own ends. Subsequently, actors with complementary resources often coalesce. Secondly, there needs to be compatibility of goals and strategles of members. Subsequently, the larger the ccalition the more "fragile" it is and the more limited 1 ts goals and viewpoint. 12

\section{Summary: :}

All of the authors above have concerned themselves with analyzing power in decision-making in terms of what can be called a "decisional model." It is one of the general methods described by Clark. In his terms, it ccnsists of a history of specific 
decisions and identification of those invloved in the decisions and those who were successful. The other writers, Banfield, Dahl, and, to some extent, Polsby, utilize an analysis of decisions and their opponents and proponents to assess power and influence. They all define "influence" in terms of one actor belng successful in imposing his decisions, intentions, and interests upon another actor. Polsby qualifies this phenomenon with the assertion that, while this may be true, it rarely occurs as a zero-sum result. Banfield, Dahl, and Polsby maintain that actors utilize their resources to attain their goals which means to increase their interests or domain. In terms of differences, Banfield tends to 1dentify influence with the possession of power resources; Dahl identifies influence with not only the possession ("potential") of resources but with whether and how they are used ("actual"); Polsby 1dentities influence with the actual outcome of decisions which is usually coalitional sharing, instead of zero-sum vanquished or victor.

\section{B. Structural:}

The structural element of a power analysis of decisionmaking is basically concerned with the internal and external operation and ordering of the power and decision-making relationships of the actors involved.

1. Internal

The internal structure of organizational power in decisionmaking will be reviewed first. The views of flve writers, Long, Dror, Presthus, Llppett, and Lindblom will be considered. 
In an article concerned more with intraorganizational dec1sion-making, Norton E. Long analyzes decision and policy-makIng as a political system. He emphasizes that organizational distribution of labor fosters the proliferation of expertise in: specific problem areas to specific individuals who become "virtual representatives of the problem area in the decisional process." Fithin organizations this leads to the departmentalization of interests with the formation of "extra-organizational constituencies." The "specialized" expert within the organization ccmes to relie upon this as a "political base" to support "his position in the internal decision-making process." 13 The relevance of this political dynamic to interorganizaticnal coalition members is evident in their preservation or promotion of what warren calls organizational "domain." This "domain" 18 analogous to Long's departmentalized "Interests" of expert organizational actors.

Some notions about internal structural decision-making variables of broader application are presented by Yehezkel Dror. Not all of Dror's propositions will be mentioned, because his primary interest is in developing an "Optimal Model" for decision-making and several assertions are not relevant to the purposes of this paper. Those generalizations which are relevart will be discussed according to Dror's arrangement of them in what he regards to be the basic units of systems of decision-making: "Individual, small-group, and organizational."

Significant "Individual" decision-making subunit characteristics and influences of each decider include the1r: (1) Ind1ridual characteristics, (2) "emotional-physical state", (3) opin- 
Ion giving environment, (4) perception and avallability of the data. 14

The only really significant and relevant "small-group" subunt decision-making characteristics and influences concern the group's "structure and history," the relationships among particlpants, group leadership, "the formal role-definitions of the group, and the nature of the 1ssue to be dec1ded." 15

Useful "organizational" decision-making subunit character1stics, processes, and structures include:

(1) Fow Instances of "formal rules and doctrines."

(2) Only a few "sophisticated officials" are conscious of and able to manipulate decision-shaping forces.

(3) Organizational decision-making generally "follows sem1structures, that are mainly informal, charnels and modes" of "traditions, power relations, and formal divisions of work."

(4) Organizational decisions are the outcome of its many "subdecision units."

(5) "Bargaining and coalition formation."

(6) Few "clear operational goals," "little data" and "limited search for alternatives." 16 "

Also concerned with the internal structure and dynamics of organizational decision-making is Robert V. Presthus. He 1s primarily interested in organizational authority on the level of interpersonal relationships in organizations. He defines authorIty as a "transactional process" of "interpersonal relationships." In this process authority is validated by legitimation. based on four variables: "technical expertise; formal role or position in the organization's hierarchy; rapport with others; and Individual psychological deference to authority."17 This approach falls to give consideration ta manj power variables. Another psychological view of authority processes which 18 
deeply concerned with power relationships is given by Lippitt, et. al.:

(1) In groups a real consensus upon who is powerful tends to occur;

(2) A group member is more likely to accept direct attempts to influence him from a person he defines as powerful;

(3) The average group member w1ll tend to initiate deferential, approval-seeking behavior toward higher power cholces. 18

Charles E. Lindblom has analyzed declsion-making on the level of policy formation in part in terms of authority and of informal systems of cooperation.

Lindblom's definition of authority includes that "if $x$ can routinely exert power or influence over $y$ because y accepts: a rule that he obey, then $x$ has authority over $y . "$ Authority is limited and specific. It 18 also a "concession" to obey by the "controlled" to the "controller." In situations "Where A lacks authority over $B$, he wlll use his authorlty elsewhere to achleve an influence on B." He further maintains that structural and rule changes tend to be revolutionary if they are of drastic proportions. Consequently, status quo influences usually remain predominant and changes are tjpically "Incremental." 12

Also related to decision-making for Lindblom is the significance of informal systems of cooperation. He principally is concerned with the process whereby policy makers adjust their interests and goals mutually through informal processes. The methods of adjustment include: (1) "negotiation," "mutual persua sion" or exchanging "threats and promises," (2) "creating and discharging obligations" - network of mutual "debts," (3) "thịd persons," (4) "direct manipulation," - use of authority to in- 
Iluence others, and (5) "adaptive adjustments" defer to those with higher knowledge and authority. 20

Summary: The internal structuring of organizational decisionmaking is essentially concerned with two issues: leadership and process. Long and Presthus both Vlew expertise as a source of organizational decision-making authority. In addition, presthus, as well as Lindblom, regard formal role and rule defining author1ty as another basis of leadership. Both Presthus and Lippett recognize the significance of individual deference to authorits among the less powerful. Iippett maintains that authority also results from group consensus as to who is most powerful. In coalitions formal roles would tend to be minimized because of 1 ts usually being an informal group, and deference to power would be of minor impact due to the operation of the pursuit of self interest. This would tend to leave expertise and consensus as the most likely sources of authority.

Structures evident in declsion-making processes are alluded to by Dror and Lindblom. They both regard the process to be highly informal and characterized by bargaining and manipulation. For Dror, the informality of structure extends to rules, roles," methods and operations in decision-making. These seem quite con sistent with the concept of coalitions as ad hoc, informal entities.

\section{External}

The Implications of external structures in the power anelysis of coalitional decision-making will be considered next. The 
writers reviewed who discussed this toplc area included: Reid, Zald, and Dror.

William Re1d deals with external relationships on the inter-organizational level. He ldentifies three possible "modes: of organizational co-existence:" Independence, interdependence, and conflict.

Organizations are independent of one another, when they do not need the resources of the other to achieve their goals and when the other is not interfering in their "goal achlevement." Interdependence exists when organizations see their own goals to be more efficiently realized with the supplement of the resources of the other. Their goals need not be identical, but the. perception of the organizational interdependence must be consclous. Conflict arises when the goal attainment of one or more organizations takes place at the cost of the goal attainment of others. 21

Mayer N. Zald discusses the conditions affecting whether formal organizations will be likely to co-ordinate and co-operate with each other. The greater the marginal profits of an organization and/or the greater the symblotic relationship between agencles, the greater the likelihood of co-ordination. The greater an organization is committed to a set program and strategy, the less the likelihood of co-ordination. 22

He maintains that "Organizations, in attempting to achieve ends, form external alliances, curry favor, and conform to the requirements of agents having greater power." The extent to which these relations become stable for a member organization (focal) 
io Important, because:

First, the greater the sanction and resource control of the other party, or the coalltional alliance, the less the autonomy of the focal organization ....

Second, the more a focal organization is bound into a stable extermal political structure, the more areas of internal policy-setting are influenced by the coalition. 23

Dror is concerned about the significance of coalitions for external policy execution. He maintains that coalitions are essential in this regard. Some of the polnts which he regards as relevant to policy-making include:

(1) The probability of forming a coalition able to execute a policy depends upon the characteristics of the policy, power distribution, and the structure and tendency to form coalitions by the "involved social and political institutions."

(2) Given number one, the formation of a policy is significantly shaped by the need for a strong enough execution coalition.

(3) The need to form a coalition limits the possible alternatives but does not eliminate the "freedom of cholce" of pol1cy-makers.

(4) Each potential coalition member decides whether to join based upon power gain and value system. 24

Summary: While distinct in their approaches to the external

structure of coalitional deciaion-making, there are definite links between the propositions of each author. The common elements divide into the basis or motivation for interorganizational co-ordination and into the implications for the autonomy of members in dec1sion-making.

The commonly identifled motive for coalition formation is self Interest: either to expand or to protect one's domain. Reid says that independence exists between organizations when they do not need the resources of others. On the other hand Re1d says that interdependence arises when organizational goals 
are realized or, protected better with the assistance of the other's resources. In like manner, Zald sees co-ordination in instances of marginal profits where the resources of other organ1zations are desirable. Dror maintains that members join coal1tions to gain power, promote thelr value system or better assure the successful execution of a policy.

The autonomy of coalition members, according to Zald, is Iimited relative to the coalition's control of resources and member involvement in a stable coalitional, political structure. Dror, on the other hand, looks at the limltations of alternatives the coalition can pursue as a whole, as the result of being composed of members of various interests.

\section{Exchange:}

The subject of exchange in power analysis of coalitional decision-making will be examined next. It provides a complex set of variables to be analyzed. Nuttall, Scheuch, and Gordon present broad conceptualizations of the ccnditions of influence and exchange. Adrian and Press present an analysis of cost, while Clark, Re1d, and Blau discuss types of exchange situations.

\section{Conditions:}

The first model to be reviewed which analyzes the area of resources and exchange is done by Nuttal, Scheuch, and Gordon. Their model seeks a "conceptualization of conditions of influence." The1r typology of influence is bullt upon two central dimensions of the actors: "(1) actual access to relevant re- 
sources ... and, (2) whether or not others in the system credit him with this possession." 25

Some of the key concepts around resource access include sanction, resource, and authority. They define sanction as "anything which can be applied to a person, group or collectivIty (an actor) which the given actor subjectively defines as rewarding or harmful." Resource is defined as "anything which allows one actor to control, provide, or apply a sanction (pos1tive or negative) to another actor." The actual process of sanctioning is thus the "actual use of resources to reward or harm another." Within this scheme authority is "tho legitimated 'right' of the certified incumbent of a position to make binding commitments regarding the collectivity's policies and resources, and to direct the activities of his subordinates." In the phenomenon of "Influencing the outcome of decision-making," the resources of an actor are either direct (own) or indirect (through others) and the power (control) is "legitimated" (authority) or "not leg1timated" (unauthorized, coercion or deterence). The strategles of influence which they identify are: (1) "persuasion," (2) "Inducement" (3) "invoking obligaticn," (4) "structuring" (available alternatives), (5) "manlpulating the perception of these alternatives," (6) "diverting the other's attention," (7) "coercion." inother key concept is "generality" of resource which "denotes the number of situations (or contexts) and actors for which the very same resource is effective in influencing." In an exchange of resources there are two actors: "one of whom possesses" and the other a "receptor." 26 
In order to analyze a particular decision-making process 1t is 1mportant to consider: "(1) the types of resources each actor possesses, (2) the presence of receptors for them, and (3) the type or mode of resources which is crucial for the decision: being made." Also the extent to which an actor can transform his resources into other types is basic to his influence. Furthermore, in analysis, the typology which these writers propose is constructed around two basic dimensions: "(1) the actual ab1z1 ty to apply a resource in sanctioning if payof time comes, and (2) the bellef of the other actors that the actor possesses or controls the resource which would allow him to sanction. The cross-cutting of these two dimensions results in four categories of influentials:

ACTUAL ACCESS TO. RESCURCES
PERCEIVED ACCESS TO RESOURCES Yes

\begin{tabular}{ll|l}
\hline Yes & Manifest Influence & $\begin{array}{c}\text { Potential } \\
\text { Influence }\end{array}$ \\
\hline No & Reputed Influence & $\begin{array}{c}\text { Without } \\
\text { Influence }\end{array}$ \\
\hline
\end{tabular}

The authors then state hypotheses about each category of actor:

(1) "Actors without Influence" ..."w1ll try to change the mode or structure of a decision-making system."

(2) "Actors with reputed influence" and who know it "will try to arold a demand for pay-off sanctions." Also, in systems with many crises, few actors will have "reputed influence" while decision-making systems with few recent crises w1ll have many actors with "reputed influence."

(3) "Actors with potential influence" once they sanction usually are seen by others as having consumed their resource and become "without influence" or others believe it is consumed when it is not and the actor remains in a situation of "potential influence."

(4) "Actors with manifest influence" will influence decisions 
mostly by the "Invocation of resources." Whether they use up a resource after a particular decision and icw others view them will determine in which of the fcur categories they w11l be. 28

Other key hypotheses include:

(1) The order of readiness to sanction will be "potential," "manifest," "reputed."

(2) Except for actors whose goal is to increase their influence, actors will avold "pay-offs" unless they will lose influence if they do not. 29

\section{Costs: :}

The next writers, Charles R. Adrian and Charles press, are: interested in "decision costs in coalitions." While the basis of the discussion is coalitions, the main focus is on the costs involved in the formation and decision-making of coalitions. The notion of coalition which they use is related to the notion of a subunit of a larger formal body. This subunit, however, is the dominant force in the formal group. They define a "winning coalition" as "any portion of the group that can decide to do or not to do something that is on the agenda of the group and over which 1t has competent authority." Once the formal rules decide what is needed for a winning coalition, the size and composition of the coalition is in theory set by the total of the "decision costs involved for participants." The "costs" are influenced primarily by three principles: (1) "unanimity principle" group pressure for unanimity (derived from small group theory), (2) "Bize principle" attempt to achieve "minimal winnins coalitions" to maximize "payoffs," (3) "Indispensible membership principle" deals with the situations in which certain powerful parties must 
be included for it to succeed. 30

The authors next are interested in discussing the different types of "decision costs." These include: (1) "Information: costs," (2) "responsibility costs," (3) "Intergame costs," (4) "division - of - payoffs costs," (5) "dissonance costs," (6) "Inertia costs," (7) "pressure - of - time costs," (8) "persuagion costs." 31

\section{S1tuations:}

There are three authors who present somewhat differing views of the situation of exchange. Clark characterizes it by mutuality, while Reld and Blau contend that conflict and inequality are predominant in exchange situations.

For Clark the crucial stage of the formation and exercise of power occurs when "one actor is able to offer to others some kind of commodity which places them in his debt." In situations of mutual, reclprocal exchange, he has developed five possible relationships: (1) "reciprocation in kind," (2) "reciprocation ....of an entirely different sort," (3) "noblesse oblige," (4) Institutionalized "altruism," and (5) "clrcular" "path" of exchanges. 32 He adds three qualifications of the exchange system: (1) "the more general the resource - ... ut1lity ... d1verse .... the greater the potential for extension of the exchange system;" (2) "the larger the number of resources ...; the more direct, complex, and extensive exchanges in the system may become;" (3) "the greater the consensus among members of a soc1al system on basle values ... the more extensive, complex, and 
indirect may be the exchange relaticnships among members of the system." 33 For Clark, there are three basic categories of exchange values of resources: "prestige value," "institutionalization importance," and "power value." 34

Reid's notions of exchange are derived from his interpretation of inter-organizational conflict. The first type of conflict is the "competitive sltuation" wherein there is a struggle over acquiring scarce "resource inputs." The second type is the "bargaining situation" wherein disagreement occurs over what and how much of resources are to be contributed by whom in exchanges. The third type is the "legitimacy issue" concerned with disputes over "output of resources" by one organization as defeating the goals of another. If this is done, organizations can refuse to legitimate one another's gorls and domains. 35

Peter Blau's scheme assumes that inequalities in power exist and develop among actors. In instances of the exercise of power by a more powerful actor upon a less powerful actor, the exchange can be analyzed through the use of a model he has formulated. The key elements in this structure are: "alternatives to compliance". (cholces to less powerful for noncompliance), "cond1tions of independence" (essentials to less powerful to be noncompliant), "requirements of power" (essentials for powerful to force compliance), and "structural implications" (areas involved that should be studied). The scheme is as follows: 


\begin{tabular}{|c|c|c|c|}
\hline $\begin{array}{l}\text { Alternatives } \\
\text { to Compliance }\end{array}$ & $\begin{array}{l}\text { Conditions of } \\
\text { Independence }\end{array}$ & $\begin{array}{l}\text { Requirements } \\
\text { of Power }\end{array}$ & $\begin{array}{l}\text { Structural } \\
\text { Implications }\end{array}$ \\
\hline $\begin{array}{l}\text { 1. Supply in- } \\
\text { ducements }\end{array}$ & $\begin{array}{l}\text { Strategic } \\
\text { resources }\end{array}$ & $\begin{array}{l}\text { Indifference } \\
\text { to what others } \\
\text { offer }\end{array}$ & $\begin{array}{l}\text { Exchange and } \\
\text { distribution of } \\
\text { resources. }\end{array}$ \\
\hline $\begin{array}{l}\text { 2. Obtain } \\
\text { elsewhere }\end{array}$ & $\begin{array}{l}\text { Avallable } \\
\text { altematives }\end{array}$ & $\begin{array}{l}\text { Monopoly over } \\
\text { what others } \\
\text { need }\end{array}$ & $\begin{array}{l}\text { Competition and } \\
\text { exchange rates. }\end{array}$ \\
\hline $\begin{array}{l}\text { 3. Take by } \\
\text { force }\end{array}$ & $\begin{array}{l}\text { Coerc } 1 v e \\
\text { force }\end{array}$ & $\begin{array}{l}\text { Law and } \\
\text { Order }\end{array}$ & $\begin{array}{l}\text { Organization } \\
\text { and different1- } \\
\text { ation. }\end{array}$ \\
\hline $\begin{array}{l}\text { 4. Do } \\
\text { without: }\end{array}$ & $\begin{array}{l}\text { Ideals } \\
\text { lessening } \\
\text { needs }\end{array}$ & $\begin{array}{l}\text { Materialis- } \\
\text { tic and oth- } \\
\text { er relevant } \\
\text { values }\end{array}$ & $\begin{array}{l}\text { Idealogy } \\
\text { formation }\end{array}$ \\
\hline
\end{tabular}

Summary: The section on exchange has had writings, which not so much disagree among themselves, as much as, they complement each other.

Nuttall, et. al. present a model which stresses the cond1tions of influence and exchange, which are basic to power analy818. The notions of percelved and actual influence are helpful to coalitional analysis, especially since coalitions in their early stages are characterized by a lack of inter-member familiarity,, which, in turn, would inftially base a great deal on appearances. A gamut of strategles could also be ut1lized. The three analytical questions pertaining to resources are useful tools 
and directly pertain to the areas considered by the other "exchange" writers. These questions concern: (1) each actor's resources, (2) presence of receptors for them, (3) type of resources necessary for the decision being made.

Adrian and Press are concemed about the types of costs incurred by decisions, which in turn require resources to support them. They are concerned with the feasibility and consequences of coalitional decision costs and variables influencing them, such as, the unanimity and size principles and the impact of the indispensible nember.

The only real area of disparity among the writers is found between Clark, and Reld and Blau. Clark characterizes exchange relationships as mutual exchange and co-operation and consensus, while Reid and Blau maintain that situations of exchange are based on inequality and conflict among members. In coalltional behavior, it is concelvable that elther consensus or conflict relations could exist depending upon the level of scarcity of resources and interdependence or dependence of actors.

\section{Process Analysis of Decision-Making}

The actual process of decision-making in coalltions will now be addressed. The literature reviewed was of a broad scope, and the authors did not specify coalitional dynamies for their principal focus of analysis. However, as with the writers reviewed for the section on power analysis, these writers secondarily covered issues relevant to coalitions. The two main areas alscussed in these works are decision-making typologies and phases. 


\section{A. Trpologies:}

Thls section presents different schemes that have been developed to categorize dec1sion-types. The authors who were reviewed were: Braybrooke and Lindblom, W11liam J. Gore, and Harvey and M111s.

Braybrooke and Lindblom have formulated a typology that 1s constructed around two focal concepts: (1) degree of change brought by decision, (2) adequacy of information and understanding avallable to the decision-makers. Their decision types in-. clude:

(a) decisions that effect large change and are guided by adequate information and understanding; (b) decisions that effect large change but are not similarly guided - hence, at an extreme, blind or unpredictable decisions; (c) decisions that effect only small change and. are guided by adequate information and understanding, and (d) decisions that effect small change but are not similarly guided, being therefore subject to constant reconsideration and redirection. 37

Expressed in a grid box 1t appears as follows:

INFORUATION

CHANGE

Large

Small adequate inadequate

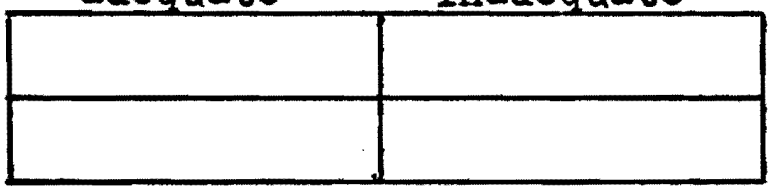

William J. Gore attempts to develop a typological model which also addresses itself to the variable of "change." It is Gore's contention that "recurring" or "programmed" decisicns have been the only types of decisions studied while "nonrecurring" and "nonprogrammed" decisions have been left unaialyzed. 38 Be then delineates a typology which attempts to incorporate both main categories of decisicns in a three element continuum: 
1. "Routine decisions," "correspondence between the prefabricated response and the response required by the situation."

2. "Incremental change" and decisions, "to adjust to an ant 1c1pated state of affalrs." Usually operates by way of informal procedures based on experience. It is more apt to concentrate upon "negotiation and development of new understandings," because it focuses upon problems and not tasks (routine decisions).

3. "Innovative dec1sions" concern a "major change in activity and operation which leads to a change in goals, purposes, or policies." 39

This model also incorporates an analytical position on the phases which these different decision types tend to follow. This w1Il be presented under the following section on "phases."

Harvey and Nills have developed a typology of decisionmaking similar to Gore's. However, they refer to decisions as solutions. Their basic categories are routine and innovative solutions. In addition, they emphasize that while routine solutions tend to be use for routine problems and innovative solutions for Innovative problems, routine solutions can be used for Innovative problems and innovative solutions for routine problem. 40 They have also expressed this model in terms of phases which will be discussed later.

Summary: There are connecting factors which run through the concepts of each of the above writers. They are all concerned with the decision response in their typologies. There are other commonalities from author to author.

Bragbrooke and Lindblom focus upon the variables of information and change. Information can be adequate or inadequate. Change can be large or small. Gore is also concerned with change. What Braybrooke and Lindblom refer to as "large change," Gore 
calls "Innovative." What they designate "small change" is comparable to Gore's category "Incremental change," adjustment. What Gore calls "routine," they do not have a designation for, but concelvably it would be classified "no change."

While addressing the issue of change resulting from a decision, Gore does not discuss information, as do Braybrooke and Lindblom.

Harvey and Mills also are concerned with innovative and routine decisions or "solutions" but draw a further distinction which none of the other writers presented - innovative and routine problems. The other authors appear to have assumed a continulty between problems and solutions. In addition, Harvey and Mills' model does not refer to the variable of information.

raking all of the authors together, there emerge three central variables: problem, information, and solution (decision). If the solution and problem types are expanded to 3 (routine, incremental, and innovative) and information to 2 (adequate and Inedequate), then a rather extensive typological scheme results. It is feasible that coalitions being informal and transcient that all problems would tend to be innovative, but this is probably only the case during the initial phases of the group. Consequently, problem type remains a viable factor. If the var1able "Information" is introduced into a typology with the variables "problem" and "solution," the question arises as to which of the two, if not both, does adequate and inadequate information refer. Braybrooke and Lindblom appear to be referring only to the "change solution," since they do not even discuss the vari- 
able "problem." However, whether actors have adequate knowledge about the problem with which they are confronted, as well as, the adequacy of the "decision solution" chosen, seem to both bare a significance in categorizing decision-making.

\section{B. Phases:}

This section concerns 1 tself with models which depict possible stages through which coalitions pass in their decision-makIng process. Again, this material is of broader applicablilty than coalitions, but it will be assessed in terms of ccalltions. Two writings referred to under the section on typologies have phase models bullt upon those typologies (Gore, and Harvey and M111s). Two other works focus on stages or phases of "rational" decision-making (Brim and Glass, and Simon).

Gore typifies the overall process and interaction of routine, incremental, and innovative decisions as a rhythmic movement. "The essential rhythm of organizational adjustment is from routine to adaptive to routine; or from routine to adaptive to Innovative and back to adaptive and eventually to routine again." 41

Hervey and Mills have formulated a sequential "path-way" model to 1llustrate the stage process. Its phases include: "Issue-perception and formation of goals," "search and the use of expectations," "cholce of solution," and "redefinition -" the attempt by others to "evade or modify such outcomes." 42 The attached 1llustrative llow chart w1ll demonstrate these patterns. It should be mentioned that for both routine and innovative prob- 
lem s1tuations "Path 1 " is usually chosen by well-established "low-threat" organizations, "Path 3" by precariously existing "high-threat" organizations and "Path 2 " by organizations at an intermediate relation to threat. 43
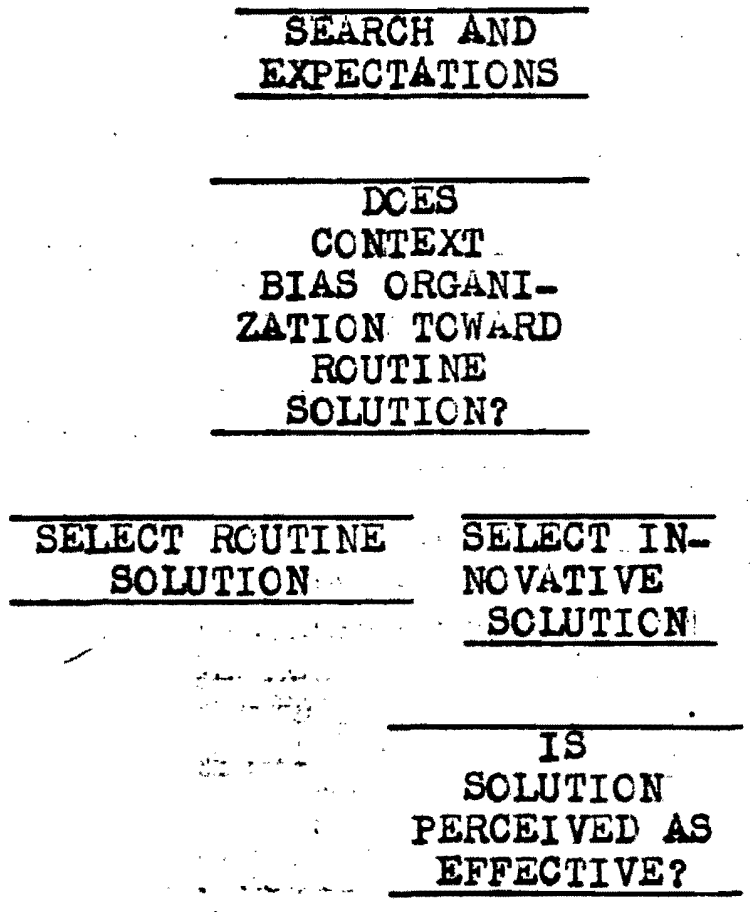

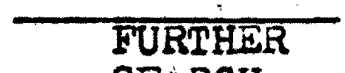

SEARCH AND EXPECTATIONS

\section{SELECT RCUTINE SOLUTICN}

Path (2)
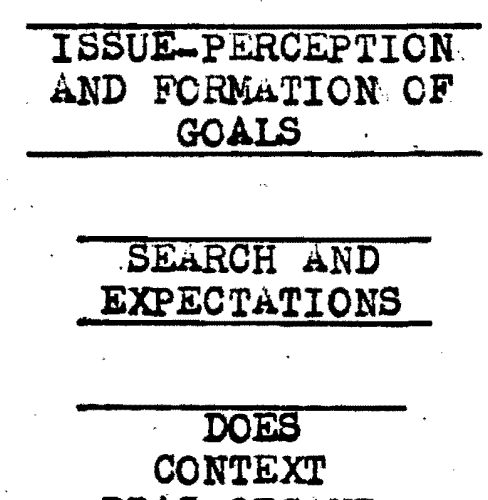

BIAS ORGANI-

ZATICN TCWARD INNOVATI VE SOLUTICN?

\section{SELECT ROUTINE SOLUTICN}

\section{SELECT INNOVATIVE SOLUTICN}

\section{REDEFINITION}

SOLUTICN

PERCEIVED

AS

EFFECTIVE?

PATH (3)
FURTHER SEARCH AND EXPECTATICNS

\section{\begin{tabular}{l}
\hline SELECT \\
INNOVATIVE \\
SOLUTICN \\
\hline
\end{tabular} \\ REDEFINITICN \\ Path (2)}


Brim, Glass, et. al, identify and discuss decision:process phases which must be gone through rationally in situations and problem areas that are new and not suited to routinized organizational behavior. They ther delineate $81 x$ discernible phases which they emphasize are applicable to the analysis of any decision. They also mention that every decision need not necessarily involve all of the six phases if some of them have been adequately áccounted for previously. The six phases in what Brim calls their customary "sequence" are;

(1) identification of the problem;

(2) obtalning necessary information;

(3) production of possible solutions;

(4) evaluation of such solutions;

(5) selection of a strategy for performance; and

(6) actual performance of an action or actions and subsequent learning and revision. 45

The same six phases are recognized by Terry clark. 46

The second essentially rational model to be summarized 18 one by Herbert A. Simon. He is concerned with rationally accounting for the environment and consequences of decision-making. He concentrates on "means and ends," "alternatives and consequences," and "value and possibility." Simon cautions sophistication in: dealing with the "means - end" issue. The directing principle is that "efficiency" demands "attainment of maximum values with Iimited ends." 47

"Alternatives and consequences" involves speculating about "baharior alternatives." This includes: (1) listing of alternative strategies, (2) determining consequences that result from each strategy, and (3) comparative evaluation of these sets of consequences. The "time and behavior" varlables can preclude 
certain alternatives on the basis of time Iimitations and previous decislons. "Knowledge and behavior" concerns should include establishing sets of expectations for the consequences of different strategies. "Group behavior" involves getting to know the strategies of the other group members and determining whether their desired consequences are the same (cooperative situation) or in opposition(competitive situation) with one's own. 48 "Value and possibility" concerns making a determination of preferences among consequences: "valuation." This is done on values of "ut1lity" (acquiring the best exchange rate) and/or the "relation of value, experience, behavior." This returns the 1ssue to means and ends; "a means-end chain is a series of ant1clpations that connect a value with the situations realizing it, and these situations, in turn, with the behaviors that produce them." 49

He concludes this approach with a definition of rationality in decision-making; "rationality is concerned with the selection of preferred behavior alternatives in terms of some system of values whereby the consequences of behavior can be evaluated." He then relates that the rationality is relative to whose system of values the goals are defined by. 50

Summary: While Gore is basically devising a ryhthmic movement of phases, Harvey and Mills' phases are concerned With representing the possible mixed combinations of innovative and routine problems and solutions and their reconsideration in the decision-making process. Gore's model much more closely approximates actually 
distinct phases in decision-making.

The two rational models contain phases which are quite similar. It should be noted that Brim, Glass, et. al. consider the "rational" model to be applicable in nonroutinized decision. situations. The Brim and Simon models both essentially contain the following phases: (1) Some review of information and alternatives, (2) determining possible solutions and consequences, (3) comparative analysis of (2), (4) choice among them, (5) performance of actions. They differ in that Brim lists an initial step of problem identification, and Simon does not. Yet, Simon includes an analysis by each actor of the others' strategies and goals so the group can assess their situation as cooperative or competitive. Brim does not specifically mention this stage, however, 1t may be implied in. the phases which determine and compare different possible stategles and solutions.

In coalitions, the internal situation (cooperation or competition) could greatis influence whether a rational model w1ll at all be feasible in the group's decislon-making process.

\section{AMALYTICAI MCDEL}

Th1s study will next present a theoretical model for analyzing the decision-making process in coalltions in light of the above readings. This model is not an hypothesis to be tested, but rather, a scheme devised to ascertain its applicability to casestudies as a step in theory building and exploratory research in the area of coalitional interorganizational behavior. The above literature delineates what other writers consider to be the 
process of decision-making and power in organizational and interorganizational behavior by way of observation and hypothesizIng. This study will draw from these works to formulate a model that is regarded to be relevant to coalitional interorganizational decision-making.

The model will be presented according to categorical areas essentially the same as those utilized for structuring the materlal in the review of the literature: decision-making power analysis (theoretical, structural, exchange) and decision-making process analysis (typology, phases).

I. Decision-Making Power Analysis:

In analyzing power as related to the coalitional decisionmaking fleld, there are essentially three analytical areas of concern. These involve theoretical, structural, and exchange questions and issues.

\section{A. Theoretical Issues:}

In analyzing the casestudies, an eclectio: approach w1ll be taken to achleren a perspective on what constitutes the phenomena of power and influence and their exercise. Power will be defined as the ability to influence other actors to be in accord with one's own position and the extent to which an actor is able to subsequently have his position accepted. These decision V1ctories will not be based on a zero-sum basis, but in terms of relative success of members as the result of coalitional decision. arrangemente. 
since this project 18 utilizing casestudies (ex post. facto interview data), the interpretations of those interviewed about all issues and actions may have been modified by memory loss,. selective recall, "output" but not "Input" and "process" vlewpoints, individual interests and their outcomes, etc. The positional method generally lacks applicability to interorganizational coalitions, since they are characterized by minimal internal formal structures. Furthermore, since the life-span of coalitions is transcient, reputational configurations resulting from internal decision-making outcomes will be minimal, especially in the early decisions of the coalition. Therefore, while positions and reputations of member units might be useful indices of power configurations, the "decisional," or historical, analysis of issue areas. and decisions seems that it will be more appropriate to the type of data involved. Yet, in combinIng a modified positional model and a decisional model, the pos1tion which a unit representative holds in his "parent organization" and that in the coalition (1f any) and his subsequent level of influence in the coalition's decision-making could be significant.

\section{B. Structural Issues:}

\section{External:}

There are certain questions which can be considered or "sought out" in the case material which could help extrapolate the power structure of the coalitions studied. Members (units) 
are part of the coalition voluntarily as autonomous units who jolned the coalition in order to expand or protect their domain (self-interest). This may also take the form of coalition membershlp based upon the need to share in the resources of fellow members. It appears that the autonomy of coalition members is lessened relative to the coalition's control of resources and sophistication of internal organization.

It appears probable that a considerable degree of the influence exercised by one unit upon another could be the consequence of extra-coalitional relations, as well as, the internal structure (minimal) of the coalition. Subsequently, it would be useful to compose a network 1llustration of member units' interrelationships both within and outside (and prior to) the coalltion. It would seem probable, that since coalitions are concerned only secondarily with issues outside of each untt's crucial intra-organizational systems, that the preservation and promotion of unit interests (autonomous), including existing interorganizational relations, would be of primary concern for members of coalitions. This could be modifled in instances where the issue before a coalltion relates to the survival of one or more of 1 ts members.

\section{Internal:}

Some Internal power structure issues need to be discussed. These should be of minimal significance, 1f, in fact, units of a coalition invest it with 'iltle authority, leadership, and formal structural elements. As a result, formal coalitional roles, 
If they were established, would carry little real power. As mentioned earlier, it is important to determine where each unit stands within their own organization, because they might only be representing a specific interest and segment of that "parent organization." Special expertise on the part of certain members could give them additional authority and power in the group. Members of the coalition will tend to develop a consensus about who is more powerful in the group. This could change considerably over the life time of the coalition, since different issue areas will be considered in which different actors will have more influence. Also, if the actors are unfamiliar with each other together as a configuration of different interests with different degrees and types of influence, only the actual testing and sanctioning of power on issueswill familiarize each unit as to the influence and power of each other unit, relative to one another. From the above and also since coalitions are informal and short term entities, It seems problable that a considerable degree of "testing" of one another's power will take place, especially early in the coalition's history. After this process, patterns of unequal influence within the coalition should more clearly emerge. If there is a single "leader" (formal or informal) in the coalition, it would indicate an "imbalance" of power hierarchically within the coalition. If there are several centers of group leadershlp, It would indicate a more "balanced" distribution of power among coalition members.

\section{Exchange Issues}


The dynamics of the power structure of coalitions is ascertainable from the actual systems and operations of exchange. Within the dynamics of exchange a resource is a commodity possessed and controlled by individual unit members or actually or potentially by the coalition as a whole, and it is valued (or sought) by the coalition units. Influence is the use of a resource of power by one unit (Influencer) upon one or more other units(influencee) to alter the influencee!s position or action so as to promote or favor the influencer's interests and goals. Types of resources can include money, friendships, jobs, votes, information, group structural controls, etc. The more general a resource is, the greater the number of situations of Influence in which it can be ut1lized. These resources can be operationalized by strategies toward other units of persuasion, obligation, inducement (reward or punishment), structuring of alternatives, manipulation of perception of alternatives, diversion of attention, and coercion.

The existence of a receptor 18.basic to the existence of Influence, because it makes possible. the control of one unit by another. The more units are dependent upon each other's resources for organizational unit goal attainment, the higher the level of co-ordination and the more frequent the exchange w111 be characterized by bargaining. The greater the co-ordination and interdependence, the more frequently relations will be characterized by mutual exchange. The greater the singular commitment to individual unit goals the lower the level of cooperation. The greater the competition for resources sought, the greater the group con- 
flict. - this includes existing resources and/or expansion of resources. The higher the relationship between resources avallable through membership in the coalition and unit goals sought, the higher the level of that unit's involvement in coalitional operations.

The analysis of the type or mode of resources necessary for the decision being made is a complex question. In terms of genera. composite coalitional resources, different issues often demand different types of resources to be exercised. The types of resource "costs" that can be incurred by a coalition unit, subgroup of units, or full coalitional group can include: (1) information, (2) responsibility (for taking a certain position), (3) intergame, (4) division of pay-offs, (5) dissonance, (6) Inertia (internal restructuring of group), (7) pressure of time, and (8) persuasion to gain support of needed vote or resource. In addition, certain "decision cost" principles can alter the degree of cost incurred: size, unanimity, and indispensible member. principles.

Onits with fewer of the resources, which are necessary for a particular decision, than one or more other units can moderate their position of inability to influence a decision by overcoming the advantage of the more powerful. This can be achleved by altering in degrees the process of indebtedness and control, to a situation of reciprocation and equality. Where the more powerful do not need the rescurces of the weaker, the potential receptor(s) may possibly involve their other resource potentials as commodities for exchange. Where the more powerful control a re- 
source needed by a potential receptor(s), the weaker unit may possibly seek out alternative resources aside from the stronger coal1tion member units. These are possible phenomena to be observed in analysis of exchange interactions.

Some more specific questions could include:

1. What were the power or influence resources of each unit?

2. What were the power or influence resources relevant to each decision 1ssue?

3. Who exercised (or attempted to) influence upon whom in each dec1sion 18sue?

4. What were the resources of each unit respective to the decision issue?

5. What was the outcome?

6. What position did each unit take on each dec1sion 18sue as compared to the outcome of the decision-making process?

7. What were the goals of each unit in joining the coalition and what was the actual outcome in terms of these goals.

\section{Decision-Making Process Analys18}

$\because$

The study will now turn to the development of a model for the analysis of the decision-making process in terms of typologies and phases for interorganizational coalitions.

\section{A. Trpological Issues}

One possible typological scheme for analyzing decisional responses to problem situations is from gradations of organizam 
tional familiarity. Degrees of famlliarity with problems and with solutions (or decisions) are concelvable within a continuum of routine, incremental and innovative. A routine problem or routine solution would both have a high familiarity rating and can be characterized by the term task oriented. Incremental has the connotation of being adjustment oriented, while innovative problems and solutions are change orlented. While routine problems are usually responded to with routine solutions, incremental or innovative solutions are also possible. The same is applicable to incremental and innovative problems and solutions. If this model were to be expanded to include the variable of information and understanding (adequate or inadequate) as to the conditions of a problem situation and problem solution a far more complex scheme emerges. In this case adequacy would be defined as sufficient understanding of the demands of the problem situation and of the consequences of the problem solution for what they are: Innovative, incremental, or routine. The model would take this form.

PROBLEM SOLUTION

\begin{tabular}{|c|c|c|c|c|c|c|c|}
\hline \multirow{2}{*}{\multicolumn{2}{|c|}{$\begin{array}{l}\text { blem } \\
\text { uation INFORMATICN }\end{array}$}} & \multicolumn{2}{|c|}{ RCUTINE } & \multicolumn{2}{|c|}{ INCREMENTAL } & \multicolumn{2}{|c|}{ INNOVATIVE } \\
\hline & & adequate & Inadequate & adequate & Inadequate & adequate & Inadequate \\
\hline $\operatorname{tin} \theta$ & bdequate & & & & & & \\
\hline & Inadequate & & & & & & \\
\hline remental & adequate & & & & & & \\
\hline & Inadequate & & & & & & \\
\hline oretive & adeauate & & & & & & $-m$ \\
\hline & Inadequate & & & & & & \\
\hline
\end{tabular}


The analyticel usefulness and practical application of such a notion of "Inforration adequacy" remains dubious, espoclally in terms of casestudy data. Another means of assessing adequacy would be whether a solution was successful in solving a problem situation, or if there arose many consequences with which the coalition apparently was not prepared to cope.

\section{B. Phase Issues}

The above typology indicates possible phases in application to interorganizational coalitions. It seems probable that nearly all problem situations and problem solutions will be inrovatively oriented. This will be particularly true in the early stages of the operations of these groups. Th1s is the case because every problem situation will be new to the coalition as a group and their response will be new for the group. Once certain procedural ground mules are established and the collition gains experience, the other orientations will become involved. However, it is possible for any combination to result, but less probable.

Certain procedures or phases in decision-making seem to be relatively consistent in most situations where rationality (as well as unit group interest) is regarded as significant by the participants. These are decision-making steps or phases and should not be confused w1th group developmental stages or phases. Cne model for compartmentalizing this process as a rational development indicates the presence of these steps in decision-making:

1. Issue or Problem 1dentiflcation. 
2. Information gathering.

3. Listing of alternative strategles and solutions.

4. Determination of consequences of each strategy or solution.

5. Comparative evaluation of findings.

6. Cholce of strategies or solutions.

7. Enactment of strategy or solution.

The applicability of this model $1 \mathrm{~s}$ probably relative to the degree of cooperation or conflict of goals and interests of the units comprising the interorganizational coalition. Unit biases should be expected to exist in decision-making. All seven of these phases should be examined (1f possible) from the perspective of the make-up of the coalition. However, 1ssue and interest agreement or disagreement among units are both compatible with the formation of a coalition.

\section{CASESTUDY ANALYTICAL MODEL}

Main Assertions

\section{Dec1810n-Making Power Analysig}

A. Theoretical Issues:

1. Positional

a. Internal

b. External

2. Decisional - dynamics of exchange

B. Structural Issues:

1. External: 
a. Coalition members join in order to expand or protect their domain (self-interest).

1) This may take the form of coalition membership based upon the need to share in the resources of fellow members.

2) It appears that the autonomy of coalition members is lessened relative to the coslition's control of resources and sophistication of internal organization.

b. It appears probable that a considerable degree of the influence exercised by one unit upon another could be the consequence of extra-coalitional relations, as well as, the internal structure (minimal) of the coalition.

c. It would seem probable, that since coalitions are usually concerned with issues secondary to each unit's cruclal intraorganizational systems, that the preservation and promotion of undt interests (autonomous), including existing interorganizational relations,. would be of primary concern for members of coalitions.

\section{Internal:}

a. Formal coalitional roles, if they are established, carry little real power.

b. Each unit member may only be representing a specific segment or interest of lts "parent organization."

c. Members of the coalition will tend to develop a consensus about who is more powerful in the group.

1) Different issue areas will be considered in which different actors will have more influence.

2) It seems probable that a considerable degree of "testing" of one another's power will take place, especialiy early in the coelition's history.

d. If there is a single "leader" (formal or informal) in the coalition, it would indicate an "imbalance" of power hlerarchically within the coalition.

- If there are several centers of group leadership, it would indicate a more "balanced" distribution of power among coalition members. 


\section{c. Exchange Issues:}

1. Conditions:

a. The more general a resource is, the greater the number of situations of influence in which it can be ut1lized.

b. The more units are dependent upon each other's resources for organizational unit goal attainment, the higher the level of coordination and the more frequently the exchanges will be characterized by bargaining.

1) The greater the coordination and interdependence, the more frequently relations will be characterized by mutual exchange.

c. The greater the singular commitment to individual unit goals, the lower the level of cooperation.

d. The greater the competition for resources sought, the greater the group conflict - this includes existing resources and/or expansion of resources.

e. The higher the relationship between resources avaliable through membership in the coalition and unit goals sought, the higher the level of that unit's involvement in coslitional operations.

\section{Costs:}

a. Different issues often demand different types of resources to be exercised.

b. The types of "costs" that can be incurred by a coal1tional unit, subgroup of units, or full coalitional group can include: (1) information, (2) responsibllity, (3) intergame, (4) division of pay-offs, (5) dissonance, (6) inertia, (7) pressure of time, and (8) persuasion.

c. Certain "decision cost" principles can alter the degres of cost incurred: size, unanimity, and indispenslble member principle.

\section{Situations:}


a. Where the more powerful do not need the resources of the weaker, the potential receptor(s) may possibly involve their other resource potentials as commodities for exchange.

b. Where the more powerful control the resource needed by a potential receptor(s), the weaker unit may possibly seek out alternative resources aside from the stronger coalition member units.

\section{Analytical Questions:}

There are scme specific questions which could be applied to the analysis of significant decisions of the coalition:

$\therefore$ 1. What were the power or influence resources of each undt?

2. What were the power or influence rescurces relevant to each decision issue?

3. Who exercised (or attempted to) influence upon whom in each decision issue?

4. What were the resources of each unit respective to the decision issue?

5. What was the outcome?

6. What position did each unit take on each decision issue as compared to the outcome of the decision-making process?

7. What were the goals of each unit in joining the coalltion: and what was the actual outcome in terms of these goals?

II. Dec1sion-Making Process Analys 1s:

\section{A. Typological Issues:}

1. Degrees of familiarity with problem situations and solutions (or decisions) are concelvable within a continuum: of routine, incremental, and innovative.

2. While routine problem situations are usualij responded to with routine problem solutions, incremental or innovative solutions are possible. The same is applicable to incremental and innovative problems and solutions. 
3. The variable of adequate or inadequate information is related to the sufficiency of understanding of the demands of the problem situation and of the consequences of the problem solution for what they are: innovative, incremental, or routine.

\section{B. Phase Issues:}

1. In application to interorganizational coalitions, it. seems probable that nearly all problem situations and problem solutions.will be innovatively oriented.

2. Once certain procedural ground rules are established and the coalition gains experienced the other orientations will become involved.

3. Certain procedures or phases in decision-making seem to be relatively consistent in most situations where rationality (as well as unit group interest) is regarded as significant by the participants.

a. The applicability of this model is probably relative to the degree of cooperation or conflict of goals and interests of the units comprising the interorganizational coalition.

4. In coalitions, strong unit biases should be expected to be operative in this process (decision-making phases).

5. Issue and interest egreement or disagreement among units are both compatible with the formation of a coalition. 


\section{CHAPTER 2}

\section{Summary of Casestudy}

\section{"Child Advocacy Proposal"}

The coalition was initiated by the Metropolitan Nelghborhood Child Care Agency (MNCCA) executive committee through their executive director Mr. H. Mr. H. defined the goals of the meeting as determining (1) if local agencles wanted such a program,. (2) the geographic target area, (3) the program proposal. The 1ssue developed out of the interest and avallabllity of federal funds for a child advocacy program. The 30 representatives present agreed on the importance of the issue and showed a general agreement w1th the target area of the c1ty suggested by Mr. H. (South C1ty). Mr. H. proposed that a "planning committee" be established to develop a proposal. Those who volunteered were reople directly concerned with the geographic and/or program area involved with exception of perhaps two organizations which never became actively involved. The most significant members were $\mathrm{Mr}$. H. from the MNCCA and the local citizen nelghborhood poverty agency South City People's League (SCPI). This became. the decision-making body.

There immediately developed a conflict over official sponsorship of the program with the two most powerful members, the child care agency and the nelghborhood poverty agency, being the main contenders. No decision was made at this point, but a chalman was selected, Mr. J., who was an allyp of the poverty ageney.

- For purposes of confidentlality, all authentic personal and organizational names have been concealed in all casestudies used. 
Mr. H. at one point attempted to include two more members of his agency in the planning process with apparent failure. He also tended to allenate the other "planning committee" members with his aggressive tactics of self interest. Two lesser members of the "committee" proposed an administration separate from tre two main members, but th1s was rejected.

In the mean time, the child care agency board became hes1tant about overextending its resources by becoming involved in the proposed project. Then in the absence of Mr. H. the "planning committee" selected a proposal whlch designated the nelehborhood poverty agency as the formal grant agent. Mr. H.'s alternate, Mrs. S., roted to approve the proposal. The board of the poverty agency later officlally endorsed the proposal, but it lacked the contact with the federal sponsoring body and had to rely upon the child care agency for lialson.

A meeting of the full coalition was called upon Mr. H's roturn from talking with the granting body. The motion was made for Mr. H. and the poverty agency to write the final draft, and It was approved. It was also agreed that the final draft be sent.to the member organizations for their support and comment. The next day the child care agency board met and endorsed the poverty agency as the grant sponsor. From this point on, Mr. H. ceased his particlpation and Mrs. S. represented the child care agency but, did not participate in writing the final draft of the proposal. The coalltion never met again, and the proposal was submitted with the members' letters of support. 


\section{CASESTUDY ANÁLYSIS}

"Child Advocacy Proposal"

\section{Deciston-Making Power Analysis:}

A. Theoretical Issues: This casestudy is best analyzed in terms of internal and external positions of 1 ts influencial members, as well as, the dynamics of the decision-making actors involved. The positional issues will be delineated under an analysis of internal and external structure, and the decisional variables will be scrutinized under exchange issues. The information avaliable In the casestudy substantially limited analysis to the two princlpal actors - MNCCA and SCPL.

\section{B. Structural Issues: $2 . .$.}

\section{B.1. External:}

B.1.a. Domain - the dimension of domain protection or advancement clearly appears to be a central factor in the involvement of the significant actors. In this instance, a maximum domain expansion of $\$ 100,000$ was avaliable. Once the inftial decision was made to restrict the potential recelving area to south city, those serlously involved lessened to units that have territorial or program domains within or encompassing that area. While representatives from another poverty group and the local college rolunteered to work on the program, the casestudy indicates that they were not among the "core" committee members. It can be inferred that this is directly related to their unit's having had no self-interest gains which cculd result from their involvement. 
B.1.a.1) Resource 1nterdependence - MNCCA (Mr. H.) seems to have needed the involvement of other community agencies in the planning process in order to fulfill application procedures. It definitely attempted to ignore their 1nput. Furthermore, the other member units, especially SCPL, depended upon MNCCA's (Mr. H.'s) l1a1son with washington, as well as, its position of established influence in the child care realm, especially Mr. H.'s position as local Executive D1rector for MNCCA.

B.1.a.2) Member autonomy - it appears that the coalition' s control of the resources was unclear and that the actors tended to operate autonomously.

B.1.b. Extra-coalitional relations - Mr. J.'s previously existing position of relationship with SCPL seems to have established them as allies. MNCCA's (Mr. H.'s) relationship with the funding agent was the key to his influence within the coalition.

B.1.c. Unit interests - the decision by the Board of Directors of MNCCA that their primary concerns and goals demanded all of their resources to maintain their operations and that the new proposal was too secondary is significant in its consistercy with the analytical model.

\section{B.2. Internal:}

B.2.a. Formal roles - internal structural variables show considerable agreement with the model. The two formal positions in the coalition's history held no significant power in themselves independent of the personalities occupying them. Mr. H. briefly 
(and self-eppointedly) was "Chairman Pro Tem" and Mr. J. was the regural chalman by consensus.

B.2.b. Pepresentativeness - Mr. H.'s inability to gain support for his "dec1sion" from his own organizational unit indicates a clear instance of a coalltion member's representing only a spec1fic segment or interest of a "parent organization" and not 1t. as a whole.

B.2.c. Consensus - It is quite apparent that coalltional members quickly came to consider MNCCA (Mr. H.) and SCPL to be the two most powerful group members.

B.2.c.1) Differentlal power - it became obvious after considerable testing that SCPL was more dominant when it came to gaining the support of fellow coalltion members, except for MNCCA (Mr. H.), while yircCs (Mr. H.) had a dominant position with respect to infomational and organizational ties to the funding source.

B.2.c.2) Testing - the testing process was quite spparent especlally in the early stages of the coalition.

B.2.d. and e. Single or multiple leadership - the emergence of two centers of real leadership within the coalition demonstrates a relatively "balanced distribution of power" between the main: contestants.

\section{Exchange Issues:}

C.1. Conditions: 
C.1.a. Resource generality - the two main actors, MNCCA (Mr. H.); and SCPL, had resources of relative generality which they frequently utilized. MNCCA's (Mr. H.'s) main resources were information and program liaison controls. These resources were employed in particulariy crucial decisions, e.g. the final vote of MNCCA's board. If the board had sanctioned Mr. H. With the full use of his potential resources, it appears that his influence could have been dominant.

SCPL, on the other hand, relled upon the resources of frlendship and rotes. Mr. J. was closely allied with SCPL, and the "planning committee" voted in SCPL's favor. These resources were relatively general and effective for internal coalitional decisions, but MNCCA's (Mr. H.'s.) external resources tended to at least be potentially decisive in that realm.

In addition, MNCCA (Mr. H.) had an established program domain in child care, while SCPLi had established territorial domain in South City.

C.1.b. Resource dependency - the degree of mutual dependency among this coalition's members is somewhat vague in view of the above. SCPL and MNCCA (Mr. H.) appeared to be interdependent, espec1ally SCPL V1s a V1s. MINCCA (Mr..H.), yet the two were clearly in open conflict. If the assertion of the model is viable, it may require certain modifications to explain the dynemics of this casestudy. One possible solution is that SCPL and the other coalition members, excluding MNCCA (Mr. H.) functioned in an apparently consensus manner. This could be based upon 
their mutual dependence for internal coalitional resources. On the other hand, MNCCA (Mr. H.) was self-sufficlent in external resources and never attempted to bargain with the other members in terms of actually making the proposal application, other than pseudo consultation. MNCCA (Mr. H.) did not involve 1tself in: the internal workings of the coalition, apparently viewing their resources as unessential to attainment of its interest goal. SCPL however, did attempt to bargain directly with the MNCCA board because of SCPL's position of considerable dependency in the area of external resources to effectively influence the attainment of 1ts goal.

c.1.b.1) Mutual exchange - the greatest mutual exchange took place between SCPL and the other coalition members, except MNCCA (Mr. H.). While the mutuality of the interdependence might be questionable, there appeared to be a genuine mutual exchange between the MNCCA board and the "planning committee." The board endorged SCPL, while the "planning committee" provided a vehicle whereby MNCCA would not over burden 1 ts own commitments and, at the same time, permitted it to promote community child care services.

C.1.c. Unit goals - SCPL and MNCCA (Mr. H.) both clearly demorstrated exclusive interests in attempting to expand their organ12ational domains, through seeking to obtain program control for each of their respective organizations. This resulted in a low level of cooperation. Two members with a lower degree of commitment, Mr. A, and Mr. B., attempted a cooperative compromiso 
of establishing a separate administration, but were uninfluenclal and unsuccessful.

C.1.d. Resource competition - Again, SCLP and MNCCA (Mr. H.) const1tuted the main contestants in competing for the potentialig avallable resources, and this provided the principal basis of the conflict within the coalition.

C.1.e. Member profit - SCPL's main access to the program funding was initially through the coalition, and later with the MNCGA board, and SCPL's coalitional involvement was considerable. However, MNCCA's (Mr. H.'s) best access to the resources was from outside of the group and, consequently, 1ts actual involvement in the coalition's operations was minimal and often token.

\section{C.2. Costs:}

C.2.a. Differential resource issues - as indicated above, C.1.b., there appeared to be two principal areas of resource utilization in this casestudy - Intemal and external. Those decisions which were internally orlented, demanded the use of internal coalitional resources, and the member who had predominant assets in that area (SCPL) was most successful in those issue areas. On the other hand, external decisions required external resources and the dominant member in that dimension, MNCCA (Mr. H.), was mainif successful in those decisions (until Mr. H. lost his sanction to utilize those resources).

C.2.b. Costs incurred - the main "costs" Incurred by MiNCCA (Mr. H.) 
were lts "responsibility costs" and "Intergame costs" for actions taken outside of the coalition 1tself, which quickly lost Internal support for its position. SCPL's main "costs" were "Information" and "Inter-game" in its dependence upon MNCCA (Mr. H.) for access to the funding source.

C.2.c. Principles - the "unanimity principle" was operative in this coalition in that there ultimately was required group consensus about the proposal to be submitted. Furthermore, the "Indispensible member princlple" was apparent with respect to MNCCA and the position of its Board.

\section{c.3. Situations:}

C.3.a. Resource independence of powerful - while the information. is insufficient frcm the casestudy, it could be speculated that the weaker coalition members sought to somehow influence the coallition's operations through the use of their main resource,, rotes, and did this by joining forces with the weaker of the two most powerful coalition members, SCPL, who was substantially dependent upon their resources, and whom they could more readily influence. At the same time, SCPL externally weaker than MNCCA (Nr. H.) ut1lized its main resources - control of coalition votes, friendshlp, and territorial domain - to match the resources of MirCGA. (Mr. H.).

C.3.b. Resource control by powerful - where NiNCCA (Nir. H.) controlled access to information and the funding body, SCPL attempted to go directly to the MNCCA board to usurp Mr. H.'s basis of 
resource sanction. When the group chose SCPL to be the formal grant agent, it was suggested that SCPL's director be in contact with Washington, as well as, Mr. H. In the decision to choose a committee to work on the finel draft, Mr. H. seems to have ut1lized the non-planning committee members to vote to include him (Inferred from casestudy data). Also, after the meeting in which Ur. J. was selected chaiman, Mr. H. took it upon himself to call another meeting and sent the notice to the "planning committee" and to two MNCCA officials - possibly an attempt to call upon more resources.

D. Analytical Questions:

D.1. Power resources:

\begin{tabular}{lll} 
MNCCA (Mr. H. and Mrs. S.) & SCPL & Others: \\
\hline Information: & Friendship & Votes \\
Crucial external contacts & Territorial domain Program domain: \\
Program domain & Vote \\
Vote & Control of votes
\end{tabular}

D.2. Win coalition decision issues and relevant resources:

MAIN ISSUES

1. Target area

2. Planning Committee

3. Cha1riman

4. Separate administration

5. Formal grant agent
RELEVANT RESOURCES

Votes, information

Votes, members, information, program domain, territorial domain

Votes, friendship, control of votes

Votes, territorial domain,, program domain, friendship

Votes, frlendshlp, control of votes. 
6. Final draft committee

Votes, information, crucial external contacts, control of votes, friendship

7. Distribution of final draft Votes, program domain

D.3. Influencer(s) and Influencee (s): DECISION ISSUE:

INFLUENCER(S) INFLUENCEE(S)

1. Target area

$\begin{array}{ll}\text { MNCCA(Mr.H.) } & \text { Whole group } \\ \text { SCPL } & \text { Whole group } \\ \text { Others("plan- } & \text { Whole group } \\ \text { ning commlt- } & \\ \text { tee") } & \end{array}$

2. Planning Committee

$\operatorname{MNCCA}(\mathrm{Kr.H.})$

SCPL

Others

Whole group

Whole group

Whole group

3. Cha1rman

$\underset{\text { SCPL }}{\operatorname{MNCCA}(\mathrm{Mr} . \mathrm{H} .)}$

Others

SCPL and others

MNCCA (Mr.H.)

and others

SCPL and MNCCA

(Mr. H.)

4. Separate administration

(Mr.A and

Mr. B.)

MNCCA(Mr.H.),

SCPL, Others

$-2$

5. Formal Grant Agent

SCDI

Others, MNCCA

(Mrs.s)

6. Final Draft Committee

MNCCA (Mr.H.)

SCPL.

Others

Whole group

Whole group

Whole group

7. Distribution of Final Draft

MaNCCA(Mr.H.) Whole group

D.4. Issues and relevant member resources: DECISICN ISSUE: RELEVANT MEMBER RESOURCES

1. Target írea

$\operatorname{MNCCA}(\mathrm{Mr} . \mathrm{H}$.

SCPL.

Others

Whole group (0ther than above

$\operatorname{MNCCA}(\mathrm{Mr} . \mathrm{H}$.
Vote, information

Vote

Votes

2. Planning Committee

Votes

Vote, information, Próram doma1n 
3. Chasman

4. Separate Administration

5. Formal Grant agent

6. Final Draft Committeo

7. Distribution of Final Draft

\section{SCPI \\ Others}

$\operatorname{MNCCA}(\mathrm{Mr}, \mathrm{H}$.

SCPL.

Others

MNCCA (Mr.H.)

SCPL

Others-2

(Mr.A. and (Mr.B.)

SCPL

Others

MNCCA(Mrs.S.),

$\operatorname{MNCCA}(\mathrm{Mr} . \mathrm{H}$.
Vote, terr1torlal domain Votes, program domain

Vote

Vote, friendship, control of votes Votes

Vote, , program doma in:

Vote, territorial domain,. friendship Votes, program domain

Votes, , program domain

Vote, : friendship, control of votes

Votes

Vote, Program Domain, : crucial contacts

Vote, information, cruc18l external contacts

SCPL

Vote, control of votes, friendship

Others

Votes

Whole group

Votes

MANCCA (Mr.H,)

Vote, program domain:

Whole group
Votes, program domain. 
D.5. Outcome:

1. Target Area

2. Planning Committee

3. Chairman

4. Separate Administration

5. Formal Grant Agent

6. Final Draft Committee

7. Distribution of Final Draft
South city

Volunteers

Mr. J.

Rejected

SCPI

MNCCA(Mr.H.) and SCPL.

Whole Group

D.6. Member Position on Issues and Actual Outcome: $t=$ in faror.

- = against, $?=$ not known.

1. South City

2. Volunteers

3. Mr. J:

4. Rejected

MNCCA(Mr.H.) +
SCPL
Others
Whole group (O- +
ther than above)
MNCCA(Mr.H.) +
SCPL
Cthers +
Whole group +
MNCCA(Mr.H.)
SCPL
Others
MNCCA(Mr.H.) +
SCPL


-5. SCPL

Mr. A and

Mr. B

Others

MNCCA(Mrs.S.

SCPI

Others

6. MNCCA(NI.H.) and SCPL

7. Distribution of Final Draft
$\operatorname{MNCCA}\left(\mathrm{Mr} . \mathrm{H}_{\bullet}\right)+$

SCPI ?

Others ?

Whole group $\quad+$

$\operatorname{MNCCA}(\mathrm{Nr} . \mathrm{H})+$.

All Others +

D.7. Member Goals Compared With Final Cutcome:

YEIUBER

MNCCA(NR.H.)

SCPL

Others

Whole Group GOALS

MWCA Grant Agent

SCPL Grant Agent

Not Known

Not Known
PINAL CUTCOME

SCPL Granti Agent.

II. Dec1sion-Making Process Analysis: in order to asgess the casestudy in relation to typological and phase issues' assertions,, each mein decisicn (using above sequential numbers) will be placed in a table and discussed later. 
PROBLEM SCLUTICN

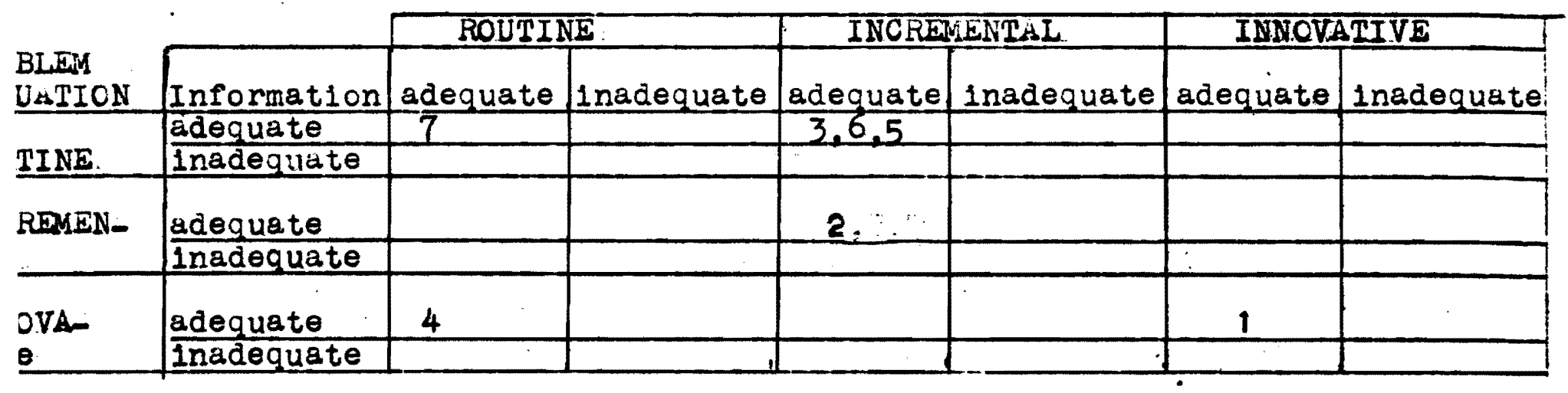

\section{EXPLANATICN:}

1. The colce of a target area was an entirely new problem for this group and the selection of South Clty was Innovative, since that section of the city had never had such a program.

2. The establishment of a planning committee is a problem which developed (1ncremental) from the planning demands of a proposal. The solution was adaptive (Incremental) based upon those becoming 1nvolved having a territorial and/or program interest.

3. Choosing a chairman is a routine occurrence group's process. The choice (Mr. J.) reflects an adaptation (1ncremental) to the interests of the core planning committeo members.

4. The proposal for seekirs a separate administration raised an innovative problem, which was dealt with in a routine mannen (rejection) with respect to the clearly ldentified member interests and resources.

5. The problem of choosing a formal grant agent is a procedural (routinized) ; outcome of the planning process and the solution is an adaptation (1ncremental) of the formation of a subcoalitional voting and interest block - as well as an adaptire 
response to $\mathrm{Mr}$. H.'s absence and the position of the MNCCA board. There does seem to be a degree of informational inadequacy with respect to falling to know that the MNCCA board had not offic1ally finalized their position. This inadequacy of information with respect to the problem situation and solution does appear to be marginal in this instance.

6. The problem of appointing persons to develop a final proposal draft tends to be a routine situation. The solution of selecting MNCCA (Mr. H.) and SCPL seems to be an outgrowth (incremental) of their mutually necessary rescurces for this task (information and contact, grant agent).

7. The problem of distributing a document is a routine matter, and declding to include all parties concerned is a routine solution with there being an adequate recognition of both dimensions.

\section{A. Iypological Issues:}

A.1. Problem familiarity - these categories seem to be relevant for classifying the above decisions and problems with the one condition that there needs to be a distinction with respect to whether degree of familiarity is to refer to each individual member unit or to the group as an entity.

A.2. Patterns - this casestudy appears to have a predominance of Instances where incremental problems were responded to with incremental decisions, but only 3out of? where situation and solution types were the same. 
A.3. Informational adequacy - seems to be a relatively insigniflcanti (and difficult to assess) variable in this casestudy.

\section{B. Phase Issues:}

B.1. Innovation - most of the problem situations were incremental, and the solutions were incremental.

B.2. Diversity - once the first major decision was made (innovat1ve - Innovative), the other orlentations appeared to be exclusively involved.

B.3. Rational phases - the casestudy information is not adequate. to determine to what extent raticnal decision-making steps were involved in each decision, while certain decisions do reflect. some of the stages. The over-riding variable influencing decisionmaking appears to be self-interest and not rationality. In this sense, raticnality could have probably determined calculated individual member decisions of self-interest, but there was not $a$ rational, comprehensive review of alternatives in an unbiased mamner. by all members jointly.

B.3.a. Relative applicability - In consideration of the above mentioned lack of casestudy information, it is difficult to assess the Impact of coaliticnal cooperation or conflict upon the utilization of raticnal decision-making steps, except that conflict dia exist, while rational1ty was not.very evident.

B.4. Un1t bias - a constant variable in decision-making in all instances seems to be the member unit's bias of self-interest and domain protection and/or expansion. This seems to be especially the case with the decisions of the "core" planning committee that in- 
nolved the members with the greatest vested interests. Ta this extent, their decisions tended to be less rational in the objective sense, but quite rationsi in 11ght of their own organization's interests.

B.5. Coalitional cohesiveness - issue and interest agreement and disagreement seem to be marginaliy compatible with coalition formation in this case. Those who essentially agreed were actively involved in the coalition (SCPI and others). Yet, their main antagonist,, MNCCA (Mr. H.), tended to be only peripherally involved with the coalition. This appears to be based upon where each of the two strongest members had the dominant resources: SCPL - Internally, MMCCA (Mr. H.) - externally.

CRITIQUE: The analytical model seems to have had a general applicability to this casestudy. Generally speaking, the "Power Analysis" segment was more useful,, while the "Process Analys1s" portion tended to be difficult to apply, primarily because of 1 ts use of terms which require further operationalization and/or revision.

Hone: specifically, there developed from this case a need to distinguish between internal and external coalitional resources, and who 18: most dominant in each and how this, in turn, affects the coaI1tional process. It also raises the question if this alters whether a coalitional group 18 of a consensus, bargaining, or dissensus or entation. Also, the role of conflict as deliberately utilized by coalition members is not fully accounted for in the model.

Also, the disparity between Mr. H. 's positions and that of his "parent organization," makes questionable whether a coalitional "parent organizaticn" can be fully ldentified with its individual coal1-. 
tional representative. If not, this inconsistency needs to be: observed and analyzed.

The eventual decision-making outcome (SCPL's being the grant agent with MiNCCA endorsement) in this casestudy raises the question whether Polsby's notion of "plurality" is not more meeningful in this case than an elitist model. MNCCA did in fact agree: not to fully employ its organizational resources of influence to broaden its domain, but rather, decided to advocate and promote a sharing of resources with a weaker organization (SCPL). This does not mean, however, that MNCCA did not profit from this sharing of resources. It is concelvable that it was necessary that they encourage such a project in order to maintain their position as the local promoter of child care' in the eyes of the funding agent. At the same time, they could not afford to deploy any of their own resources to directly seek the resources to be funding agent themselves.

with respect to the "Process Analys1s" model, the vagueness of term definitions and the tentative classification of decisions ralses doubts as to whether coalitional problem sltuations and solutions are predominantly innovative (II.B.1.). The issues of internal and external resources and involvement (based upon casestudy information) make questionable whether coalition formation is Independent of 1ssue and interest agreement or disagreement. (II.B.5). 


\section{CHAPTER 3}

Summary of Casestudy

"Black Coalition"

This coalition of black organizations was the outcome of racial and subsequent police incidents at a metropolitan high school. The local war on Poverty citizen organization in the black community Equal Opportunity Now (EON) alterred an already scheduled meeting to take up the school issue and invited parents of the school children and moderate and militant black organizations. This was the start of the coalition.

Eventually a chaiman (black poverty organization representative) was selected by the coalition. They adopted the suggestion by the princlpal black militant group (Brothers) to boycott the schools and decided to establish an alternate school to be run by the same militant group and a black studies program from a local university. They also chose to hold a community rally to inform and unite the black community. at the rally, the earlier coalition decisions were approved by the $600 \mathrm{com}-$ munity people present.

The basic method of internal procedure was agreed to be as a unit, but with a division of labor. After awhile the chalrman had to resign, because he wse an employee of the school district and was under pressure. Th1s also was the case with two other active coalition members, who were also employees of the local federally funded community action agency. The coalition's new chairman, Rev. C., was a representative of a ministerlal organization United Christian Front (U.C.F.) and was selected because 
of his moderate lmage among blacks in a hope to unify the community. Two militant organizations claimed mutual leadership with the new chairman evidencirg a widening internal rivalry.

The community school became immersed in problems. It lacked transportation, lunch, and teacher resources. The two main milltant groups then attempted to conduct the teaching allenating many parents.

The boycott was used by the coalition to make demands upon the school board. The board responded by setting up a counter group. Dissension set into the coalition with disagreements over what step to take next. The moderate chairman, under pressure from the main militant organization called for a citywide boycott. The strategy was to penalize the school its state ald money. The boycott and coalition were rapidy dying. Some members met secretly with the school superintendent without informing the rest of the coalition. The community school closed and several coalition members dropped out. Without informing the militant. member, the boycott was called off by the chairman afterit was about $2 \frac{1}{2}$ weeks old.

The main accomplishments of the boycott were an end to rac1al trouble at the high school, a changed curriculum, increased respect by white students, and the first effective unification of the black community.

\section{CASESTUDY ANAIYSIS}

"The Black Coalition"

\section{Dec1s1on-Makins Power Analys1s}


A. Theoretical Issues:

The internal and external positions and structures of the members of the Black Coalition had considerable impact in this casestudy and an analysis of them would be useful. The decisional approach also has considerable analytical merit espec1ally with respect to exchange and process issues.

\section{B. Structural Issues:}

B. 1 ExtemaI

B.1.a. Domain - all of the organizations involved in the coal1tion were based in a metropolitan black community and were concerned with protecting the interests of their people in the high school racial dispute and with protecting their organization's. legltimacy in the black community. This was domain protection, but it was also domain expansion when it came to their list of demands which sought to expand, as well as protect, black ineluence in the metropolitan school system.

B.1.8.1) Resource interdependence - there was considerable interdependence among coalition members in face of the school system because of their position of relative weakness in resources as compared to their adversary. This external imperative seems to have necessitated a united front.

B.1.a.2) Member autonomy - once the coalition began to operate it revealed little internal control of the needed resources, which were most often based with external authorities e.5. com- 
muntty action agency's withdrawal of school buses because of a fear of suspension of its funds. Also the internal organization. of the coalition was not sufficiently sophisticated to assure the group's autonomy. Instead, it was victimized by internal power struggles, which weakened the coalition in face of the relatively monolithic organizational authority structure.

B.1.b. Extra-coalitional relations - probably the three most Influenclal coelition members were the UCF, the Brothers, and Simba. A conslderable degree of the ir influence was based upor their extra-coalitional relations with different segments of the black community. UCF's constituency and image was moderate; the Brothers! and Simba's were milltantly based. These were also the centers of the coalition's real leadership: Rev. C. (UCF) was coalition chalman; the Brothers and Simba conducted the community school.

B.1.c. Unit interests - the impact of coalition members attempting to protect and promote their extracoalitional and unit interests was an extremely crucial factor in this coalition. Some of the examples of how this greatly limited resources and crumcial membership will be given. Mrs. S. had to assume a "behind the scenes" involvement, because she was employed by a federally funded program. The original chaimman, Mr.I., had to resign that position, because he had been accused by the school system (his employer) of beling in violation of his contract. Mr. D. also wharew from active support (providing school buses), because he feared a loss of federal funding for the community action 
agency, of which he was executive director. Many black teachers who were to teach in the community school did not, out of fear of losing their jobs.

\section{B.2. Interna1:}

B.2.a. Formal roles - the few formal roles within the Black Coalition carried little real power in themselves. The group's first chalrman, Mr. L. of EON, exercised little real power in the coal1tion. Yet, the second chairman, Rev.C. of the UCF, was quite influertial. The organization and operation of the community school seems to have been delegated to the local university Black studies Program, Simba, and Brothers. While each played a role, the Brothers were most influencial in its operation. Consequently, the formal role was not as significant as the power and influence of the unit filling $1 \mathrm{t}$.

B.2.b. Representativeness - most of the units appear to have represented accurately the interest of their "parent organization," w1th some exceptions. Mrs. S. and Mr. D., Community action agency, represented only a segment of their organization and its interests. This was largely responsible for their withdrawal from covert support. Rev. C.; In deciding to expand the boycott, extended himself beyond the interests and support of his moderate organization.

B.2.c. Consensus - from an aggregation of many organizations, three emerged as being recognized as the most powerful and were delegated more formal and informal authority than the rest. or these three - UCF, Simba, Brothers - the UCF and Brothers were 
the most dominant.

B.2.c.1) Differential power - when it came to being able to appeal to broad community support, leadership by UCF personnel was more influencial. However, when dealine with more conflictual 1ssues - rallies, the rival school - the Brothers and Simba were more influential.

B.2.c.2) Testing - early in the coalition, EON!s role as leader. was eroded by its lack of genuine influence and power resources. While the UCF gained control of the chairman's position, the Brothers claimed they also lead the coalition. Th1s challenging of each other's power by the two principal units continued throughout the coalition's history and was not confined to the initial period.

B.2.d. and e. Single or multiple leadership - the concentration: of most of the power in essentially two members resulted in a partial balancing of power in the coalition between the moderate and militant overall factions.

\section{Exchange Issues:}

c.1. Conditions:

C.1.a. Resource generality -- the Brothers' and Simba's main resource was an emotional and 1deological appeal. This resource was effective in stirring up support at rallies, but it was ineffective in organizing the community school. Their main resource was not general enough. The UCF had a moderate Image 
which gave it broader community appeal (its main resource), but 1t falled to be able to move the community to radical and unified militant, strike action in boycotting the schools and dealing with them with conflict tactics. Their main resource, consequently, was also too narrow.

C.1.b. Resource dependency - the member unlts were very much dependent upon each other's resources to achieve an effective boycott. This appeared to only partially and temporarlly prompt the leaders of the two factions - UCF and the Brothers - to Involve themselves in coordination and bargaining. The UCF took broad coalitions leadership, and the Brothers assumed authority over the community school. They both proved ineffective in their respective areas. Their ldeologies were also allen to one another and made coordination basically impossible.

c.1.b.1) Mutual exchange - there was little coordination, much interdependence, and relatively inconsequential mutual exchange the early dividing of authority between the UCF and the Brothers being the only real occurrence.

C.1.c. Unit goals - there was considerable commitment to indirldual unit goals and ldeologies and a low level of cooperation..

C.1.d. Resource competition - there was considerable conflict between the UCF, and the Brothers and Simba to be recognized as the principal leader and spokesman for the black community and for the possible expanded role of control of the school system. C.1.e. Member profit - there was a definite relationshlp between gaining control of the coalition's existing and potential re- 
sources and power through membership in a unifled black movement, and the goals of the two key units and factions to be the black community's spokesman, and the high level of involvement in the coalition's operations by the UCF and the Brothers.

\section{c.2. Costs:}

C.2.a. Differential resource 1ssues - the decisions of the Black Coalition demanded different types of resources. In 1llustration, the issue of choosing a chaiman required an internally noncontroversial figure acceptable to all members, if possible. The issue of conducting a rally required the resource capacity to emotionally stir the community to support the decision to boycott against a common adversary.

C.2.b. Cösts incurred - the Brothers and Simba suffered the "responsibility costs" for the outcome (fallure) of the community school, as did the UCF for their effort (fallure) to forge and lead a viable black coalition. Some coalition members became Involved in the school system's own committee and this resulted in heavg "Intergame costs" for the coalition. Dividing up of the coslition's leadership functions - the administering of the community.school and the chairing of the ccalition - resulted in inefficient "division of pay-offs costs." Perhaps the main coalition decision costs were those incurred from its internal "dissonance."

C.2.c. Principles - because of the Black Coalition's position of weakness, relative to the school system, they needed to attain: 
a unanimousiy united front. The actual result was that this "decision cost principle" - essential to the coalition's potential success - was not attalned.

\section{C.3. S1tuations:}

C.3.a. Resource independence of powerful - in terms of external 18sues, the school system did not need the Black Coalition's resources of emotional and 1deological appeal and moderate black community support. However, through the boycott, the Black Coalition sought to undermine the fiscal support recelved by the school system for the number of students and the days they attend. By this, the coalition was utilizing alternate resources as commodities for exchenge.

c.3.b. Resource control by powerful - the School System controlled the schools with their authority to teach and to graduate or not graduate students. The coalition sought to develop an alternate resource through its "communt ty school."

D. Analytical Questions:

D.1. Power Rescurces:

United Christian Front (and other moderate unitis)

Membership

Votes

Following of moderate segment of black community

Black parental support
Brothers (and other militant units)
Membership

Votes

Following of militant segment of black community

Contacts and rapport with high school and college black students 
Consensus appeal

School transportation
Emotional appeal

Contact with (potential) teachers.

Ablilty to 1dentify enemy

D.2. Main Coslition Decision Issues and Relevent Resources:

MAIN ISSUES

1. Cholce of a chairman

2. Whether to boycott

3. Children's education

4. Inform and unite support of black community

5. Function of Rally

6. Internal Unit Operation

7. Need for new chairman

8. Extent of boycott

9. Discontinuance (duration) of boycott
RELEVANT RESOURCES

Votes, broad (consensus) coalitional support.

Votes, membersh1p, black parental and student support, consensus (1nternal) appeal and emotional appeal.

Votes, membersh1p, following of moderate segment of black commun1ty, black parental support, contact with potential alternate educational resources.

Following of moderate and militant segments of black community, black parent and student support., membership, votes, consensus appeal, emotional appeal, and alternate educational rescurces.

Same as 1ssue 4 with much more emphasis upon emotional appeal and ablilty to identify enemy.

Consensus and compatibility of member units (consensus appeal).

Consensus (internal) appeal, votes, support of moderate and militant member units.

Same as issue 2 above.

Same as 1ssue 2 and 8 above.

D.3. Influencer(s) and Influencee(s):

DECISICN ISSUE

1. Cholce of cha1rman

2. Whether to boycott

3. Children's education
INFLUENCER(S)

INELUENCEE (S)

Not given in casestudy

Brothers Rest of Coalition

No more given in casestudy (unanimity inferred).

Black parents
Rest of Coalition 
4. Inform and unite rest of black community

5. Function of Ra1ly

6. Internal unit operation

7. Need for new chairman

8. Extent of boycott

9. Discontinuance (duration) of boycott
Not given in casestudy (unanimity inferred).

Black Coaliticn

Black community

Not given in casestudy (unanimity inferred).

UCF Coalition

(Not given in casestudy but, Brothers opposition implied).

Brothers

Coalition

Brothers

Black Coalition

Students

Black Coalition

UCF

Coalition

D.4. Decision Issues and Relevant Member Resources:

DECISION ISSUES

i. Choice of chairman

2. Whether to boycott

$$
\text { UCF. }
$$

3. Children's education UCF
Brothers

Brothers

UCF

Brothers

\section{RELEVANT MEMBER RESOURCES}

Votes, consensus appeal

Votes

Votes, : membership, black parental support, conseneus (internal) appeal.

Votes, members, black student. support, emotional appeal. Votes, membership, following of moderate segment of black community, black parental support, school transportation. Votes, membership, contact with potential tean chers. 
4. Inform and unite rest of black community

UCF

Following of moderate segment of black community, black parental support, membership, votes, consensus appeal, school

Brothers transportation.

5. Function of Rally

Same as issue 4 above but with much more significance to Panthers' resources of emotional appeal and

6. Internal unit ability to identify enemy. operation

UCF

Brothers

7. Need for new chairman UCF

Brothers

Same as 1ssue 2 above

8. Extent of boycott

9. Discontinuance (duration) of bojcott.

Same as issue 2 above
Consensus appeal Miltancy (I1abi$11 t y)$

Consensus (internal appeal, support of moderates, votes. Support of m111tants, votes.

\section{D.5. Outcome:}

1. Cholce of chairman

2. Whether to boycott.

3. Children's education
Mr. L.

Coalition affirmation to boycott

Community school 
4. Inform and unite rest of black community

5. Function of rally

6. Internel unit operation

7. Need for new cha1rman

8. Extent of boycott

9. Discontinuance (dur : ation) of boycott

Re11y

Community endorsement of decisions $1-3$.

Operate as a unit

Rev. C.

City wide boycott.

Boycott termination

D.6. Member Position on Issues and Actual Cutcome: $+=1$ in favor: - = against, $?=$ not known.

DECISICN CHCICE

1. MR:L.

2. Coalition affirmation to bojcott

3. Community school

4. Rally

5. Community endorsement of decisions $1-3$.

6. Internal unit operation

7. Rev.C.

8. City wide boycott

9. Boycott termination
MEMBER POSITICN

? (unanimity inferred +)

? (unanimity inferred + )
? (unanimity inferred + (unanimity inferred + )

Black Coalition +

? (unanimity inferred +) UCF

UCF

Brothers

UCF

Brothers

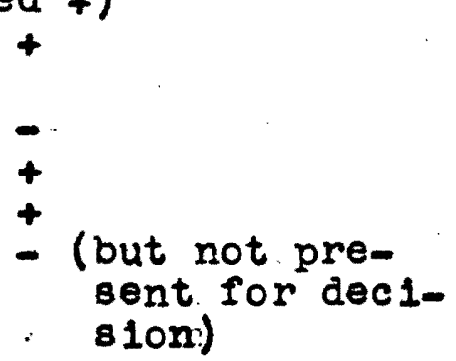

D.7. Member Goals Compared With Final Outcome:

\begin{tabular}{lll} 
YWMBER: & GOAIS & FINAL OUTCCME \\
\hline UCF & Protect black & End of school \\
& students and & trouble, curr1- \\
& expand own or- & culum charses, \\
& ganization's in- some new respect \\
& fluence in school by white students \\
& system and com- & of blacks, and \\
& munity & first effective \\
& & unity of blecks.
\end{tabular}




\title{
Brothers
}

\author{
Protect black \\ students and \\ expand own organi- \\ zation's influence \\ in school system \\ and community.
}

II. Dec1s1on-Making Process Analys1s: in order to asses the casestudy in relation to typological and phase issues'assertions; each main decision (using above sequential numbers) will be placed in a table and discussed later.

PROBLEM SCLUTION:

\begin{tabular}{|c|c|c|c|c|c|c|c|}
\hline \multirow{3}{*}{$\begin{array}{l}\text { blem } \\
\text { uation } \\
\text { tine }\end{array}$} & \multirow[b]{2}{*}{ Information } & \multicolumn{2}{|c|}{ Routine } & \multicolumn{2}{|c|}{ Incremental } & \multicolumn{2}{|c|}{ Innovat Ive } \\
\hline & & adequate & Inadequate & adequaté & Inadequate & adequate & Inadequate \\
\hline & adequate & & & & 1 & & \\
\hline & Inadequate & & & & & & \\
\hline remental & adequate & & & $5,7,9$ & 6 & & 8 \\
\hline & inadequate & & & & & & \\
\hline Jvative & dequete & & & & & 4 & \\
\hline & inadequate & & & & & & 2,3 \\
\hline
\end{tabular}

\section{Explanation:}

1. The need for a chaiman seemed to be a procedural response (routine) to the group's emergence as a coalition seeking to organize. The cholce of $\mathrm{Mr}$. I. appears to be a consequerce of the coalition's need for broad support from the black community. Their assessment of the situation as requiring a chairman reflects adequate information, but their selection of $\mathrm{Mr}$. L. seems to have been inadequately based in view of Mr. M.'s subsequent resignation because of his job's liablilty.

2. Considering and affirming the strategy and program of boycotting the high school was a definite departure from the usual grie- 
vance processes. Their fallure to recognize the community's internal dissension and lack of unity in carrying-out an effective boycott was not adequately recognized in the situation and solution assessments.

3. The situation of providing a satisfactory educational alternative and the development of a community school were innovative. As in number 2, the assessment of community resources was highly inadequate.

4. Usine a rally (solution) to unite and inform the black community (situation) was unusual. The recognition of such a problem situation seemed valid and the cholce of a rally as a means appears marginally adequate.

5. The function of this rally as a means to also gain community endorsement of the coalition's decisions seems to be an outcome of their recognition of the need for broad public support and public acceptance of their representativeness. The situation and solution seem to have been adequately appraised.

6. The sltuation of needing an internal structure for operating and the solution of doing this as a single unit are a consequence (incremental) of the group's development as an organization. The need 18 an adequate observation, the solution is inadequate if the nature of this group's members had been accurately recognized.

7. With the resignation of $\mathrm{Mr}$. L. a new chairman needed to be 
chosen to adapt (incremental) to this situation, and the selection of another moderate was a result of the earlier policy and a recognition of the coalition's need for unity. The situation and solution analysis seems perceptive.

8. The need for a new strategy developed (incremental) from the coalition's difficulties, but the solution of extending the boycott to city-wide was radical (innovative). Seeing that the situation required a new strategy was accurate (adequate), but, when the coalition was beginning to collapse from ineffectiveness, expanding its demands was an inappropriate assessment (inadequate) and response.

9. The subsequent fallure of the new strategy necessitated (Incremental) a reconsideration, and the solution of terminating the boycott seemed an appropriate consequence (incremental) to confirm formally what had already occurred in fact. These both reflect accurate analysis and adequate information.

\section{A. Typological Issues:}

4.1. Problem familiarity - the categories in the above table seem to be useful but require a degree of arbitrariness in application.

A.2. Patterns - sever of the nino main issue areas had identical problem situation and solution types.

A.3. Informational adequacy - the concepts of adequate and inadequate information added clarity in interpreting the main: de- 
c1sion: 18sues and cholces.

\section{B. Phase Issueg:}

B. 1. Innovation - only three out of nine of the main coalitionaI problem situations and solutions were innovatively orlented.

B.2. Divergity - of the main 1ssues considered, none were reganded as routine. Decisions 2, and 3 , and 4 were innovative, and the rest. were incremental. There appears to be something of a trend from innovative to the other orlentations.

B.3. Rational phases - this casestudy manifests l1ttle use of a rational dec18icn-making model. This is reflected in poor assessment of alternatives and consequences of strategles and proErams. Decisions were made without exploring whether the coal1tion had the resources necessary for successful decision execution. Two examples are the community school and the expansion of the bojcott. There were other goals (e.8. changes in schools, unlting black community), however, which were achieved raising the 18sue of whether these were perhaps the main goals of a rationally used conflict strategy.

B.3.a. Relative applicab1lity - this group was characterized by Internal conflict and a lack of rational decision-making.

B.4. Unit bias - unit biases were apparent throughout this casestudy and were signiflcant in the coalition's relative lack of success. The coalition process was marked by internal dissensiom, 0.8. Brothers claimed the chairmanship along with the ucr even: though the UCF's Rev.C. was the only elected officer. 
B.5. Coalitional cohesiveness - the degree of interest agreementi and disagreement varied with the issue, but the basic situation of internal disagreement tended to dissolve the coalition.

Critique: The analytical model's use of decisional analysie presented some limitations in the way it could be utilized with the casestudy avallable. This restricted the decisions to be analyzed to the main issues, and this did not lend itself to interpreting routine coalition problems. This is more of a 11mitation of the data than the model.

The casestudy reveals that there is no necessary connection between those in positions of formal and informal power. However, as the group developed, those with real power did in fact control actual formal authority (UCF and Brothers). It seems to have also been the case that when a formai leader was also an Informal leader, then the formal role provided access to additional power (UCF and Brothers). However, when the fornal leader had few informal power resources, then the formal leadership pos1tion had little power (Mr.I.).

Pertially in exception to assertion (1.B.2.c.2), the member unlts were testing each other throughout the coalition's history.

Assertions I.B.2.d. and e. (leadership distribution) can: possibly be combined in analyzing casestudies.

The Iindings seem to indicate that this coalition's main 1ssue areas and decisions were not overwhelmingly innovatively orlented, , challengling assertion II.B.2.

The IIndings also appear to contradict assertion II.B.5. 
In: that substantial interest (and ideological) disagreement served to fragment and destroy the Black Coalition instead of being compatible with its existence. This did, however, provide for a testing of the positions of one another among members of the black community and of the use of a black coalition. 


\section{CHAPTER 4}

\section{SUMMARY OF CASESTUDY}

"West End Community Mental Health

Center Planning Project"

i. The West End Community Mental Health Project Coalition. grew out of earlier unsuccessful attempts to find innovative alternatives to the present approach to mental health in a metropolltan area. There was also concern about the state's loss of federal funds in mental health, because of a lack of proposals.

The key leaders, "old steering committee," of this previous group eventually sought to initlate a proposal by community based agencies. They called together key West End agency executives who agreed on:developing the proposal and to. sending their own representatives to that undertaking. The "old steering committee" leaders, on their own, pre-selected a chairman and vice-chairman, who were later nominated and elected by the coalition. The deference of the new members to these leaders was also evident in their acceptance of their plan for proceeding, their working model, and their organizational format. The coalition later chose to include the P. district in the project. They also agreed to the need and requirement to Include community involvement, and set up a committee to evaluate this.

A cruclal planning conference was selected as a means of organizing and preparing the project. There was a move by the 
"old" leaders to restrict attendance, but the insistance of the other coalition members led to the opening of it to all members. The "old" leaders organized the tasks and the discussion groups for the conference, as well as, chairing all the discussion groups. The conference chose a set of goals and principles, on organizational structure, and a plan for community involvement.

There was later on an expansion of the executive committee from three of the "old steering committee" members to include "task force" leaders in the new group.

A final draft of the team plan was also submitted. It incomporated many of the principles agreed upon at the planning conference.

\section{CASESTUDY ANALYSIS}

"West End Community Mental Health Center Planning Project"

\section{Decision-Making Power Analysis}

\section{A. Theoret1cal Issues:}

Because of the apparent unanimity on most decision issues and the substantial use of formal internal structures, this casestudy will require considerable emphasis upon positional analysis and structural 1ssues. Decislonal analysis and exchange dynamics, however, w11l also be of considerable analytical usefulness.
B. Structural Issues: 
B.1. External

B.1.a. Domain - all of the members of the coalition were elther based or involved in the West End section of a metropolitan area in the fleld of social service, expecially mental health. All of these agencles had the possibility of acquiring additional staff members or funding through involvement in the proposed federally funded community mental health center project. The best way to assure their involvement would be through influencing the planning of the program. Not to be a part of such a program could even diminish their existing community role by their being out performed by a more comprehensive and effective program.

B.1.2.1) Resource interdependence - the members of the coalition were unable to achleve the project's development, approval, and gosl without the resources of the other members. The original "steering commlttee" planners (Mr. R., Mr.Y., Dr. S, Mr. M., etc.) had been unable in the past to develop a successful program, and they needed the resources, 1deas, and commitment of "key" commun1ty (West End) agencies to establish this program. At the same time, the agencies did not have the background and contacts of the "steering committee," nor the individual resources (most members were narrowly specialized, e.g. residential treatment for disturbed children, visiting nursing care, etc) to sponsor a comprehensive community mental health program by themselves.

B.1.a.2) Member autonomy - the internal organization of the coalition was highly formal and sophisticated. It made consider- 
able use of "task force" committees, marathon work sessions, and a very directive executive commlttee. This seemed to considerably lessen member autonomy. The coalition collectively controlled extensive community soclal resources with no apparently completely dominant or self sufficient (as regards the project) member or members. The potential resources of federal fundirg were completely attached to coalitional membership and activity..

B.1.b. Extra-coalitional relations - the relationships of the or1ginal "Steering Committee" group which existed prior to the West End coalition were cruclal in determining the "core" of leaders in the actual coalition. Those in this previous, and continuing, relationship were: Mr. O. (Community Counc11), Mr. Y. (State M.H. Dept.), Mr. R. (County Mental Health Bureau), Dr. S. (State Med-ical Affairs Association), Mr. M. (Nelghborhood Action Center NAC), and Mr. G. (Metropolitan Child Care Clinic). Even during the crucial coalition planning meeting at the Sunray meeting grounds, these prior relationships continued - the planning group discussion leaders were: Dr. S., Mr. Y., Mr. G. and Mr. R. The extra-coalitional relations of the other organization members were not evident in the casestudy material, however such organizations as public welfare and Community Nurses are certian to have previously existing relationshlps, but to what extent these contacts had upon the coalition's process is not evident from the casestudy data.

B.1.c. Unit interests - there was evidence that at least some of the coalition's particlpants clearly regarded their involvement 
as secondary to their unit interests. Charity Hospital was cautious in reviewing how their commitment to the program would relate to their over all program and goals. The chalrman, Dr. S., appears to have regarded this coalition as a secondary matter to his own interests as indicated by his possible lessening of involvement upon his appointment to a new position with the state. of more apparent evidence is the concern with the promotion of unit interests by the coalition's members. Probably the best and most comprehensive lllustration of this was the pattern of volunteers for the committees on the areas of concern for the project. People volunteered for the committees which concerned their organization's interest, e.g. Mr. J., Alcohol1sm and Drug Services; Rev. N., Geriatric Services, etc. They were thus seeking to primarily promote and protect their organization's interests in lieu of a: peripheral concern.

\section{B.2. Internal:}

B.2.a. Formal roles - the formal roles in this coalition were extremely important and influential. Dr. S.'s becoming chaiman 8lgnificantly influenced the power structure of the coalition. It was not only his formal position, however, but how he defined and utilized 1t ("directive" leadership) which resulted in 1 ts being a position of power. The vice-chairman, Mr. G., was in a similarly influential position, but of less impact. Their activities and positions with the "Steering Committee" enabled them to set up their own elections by the new coalition. They also determined the major initial input of members (letters by 
participants). At the seccnd meeting, it was their meeting plam and organizational format (committees to study program areas) which determined the course of action. Dr. S. also established the four main taskg to be achieved at the Sunray conference. Dr. S. and Mr. G. were also responsible for drafting the "community team" model to be completed by a special committee. They, along with a few others, were appointed to an executive commlttee that had the power to act between meetings in the program plan-. ning.

The other important formal coalitional positions were varlous committee chairmen and members. They significantiy determined the components of the proposal. The entire process worked within a highly structured system of an executive committee: and task force committees.

B.2.b. Representativeness - the "parent organization" of some members was somewhat nebulous, e.g. County Poverty Agency, County Mental Health Project, County Family Mental Health Bureau, and County Public Health Bureau. Whether their "parent organization" was the division, clinic, etc. or the oounty determines if these people represented the county as a whole (whatever that. 1s) or that division, etc. The tendency would probably be to promote the interest of the lower level segment, but evidence is lacking in the casestudy to clarify this. There did seem to be a movement at Sunray to seek out the County's relationship with the project, including the possibility of 1ts being the fiscal agent. For the coalition generally, there is no clear evidence 
indicating unit representatives substantially digressing from "parent organization" interests.

B.2.c. Consensus - to the date that the casestudy covered, the most powerful members of the coalition tended to be recognized as those in formal coalitional roles, e.g. chairman, vice-chairman, and task force committeo chalmen. This was especially the case with the chalrman and vice-chaiman. There was also the recognition of Charity Hospital as a powerful member, since it was required as the inpatient facility in the proposal.

B.2.c.1) Differential power - the structural and procedural 1ssue areas were dominated by the two elected officials. The 1ssue of agency inclusion in the planning process (committees and Sunray) were greatly influenced by all concerned coalition agency and cltizen members.

B.2.c.2) Testing - since no substantive doma1n issues had as yet arisen, little testing had occurred within the coalition. One exception was the conflict over participation at the crucial Sunray planning session in which the "leaders" attempted to restrict attendance and coalition members sought an open meeting and won. There was also the conflict by the citizen based groups over c1tizen-1nput.

B.2.d. Single leadership - the formal coalitional leadership was essentially controlled by one (possibly two) person, Dr. $S$. He also controlled the process of the group in a directive manner. While the formal leadership was "Imbalanced," the informal lead- 
ership had not as yet emerged (hypothetically it might never emerge) - so the structure of that distribution of power had not jet become apparent. Some possibilities of other centers of power Include Charity Hospital, the State, the County, Citizen participation organizations, residential and out-patient facilities. All of these members have substantial resources.

B.2.0. Multiple leadership - the formal group leadership is somewhat centralized and imbalanced, however the distribution of informal power resources among several participants indicates a possibility of the future development of several centers of group leadership.

\section{Exchange Issues:}

c.1. Conditions:

C.1.a. Resource generality - the resource of formal organizational control of the coalition was a very general resource frequentIy and effectively used by the formal coalition leaders. The applicablilty of this resource would probably tend to decrease once the stage of concrete proposal make-up and proposed project subcontracting was initiated. Informal power resources would then probably tend to be dcminant. Coalition members with more: specific resources with lower generality include Charity Hospltal's control of the only viable inpatient facility, and 1ts relative control of that portion of the proposal. Another 111ustration is the ccrtrol of the citizen participation segment by those agencies and residents with that organizational and per- 
sonel interest. There was also program and knowledge control by agencles specialized in certain problem areas.

C.1.b. Resource dependency - the process of this coalition has generally been characterized by cooperation. This has largely been determined by the pervasiveness of the project which requires the resources of a broad diversity of local West End community agenc1es. The result is that the members of the coalition need the resources of each other to successfully attain the overall pro-posal's acceptance which is constituted by program components concerned with member interests.

c.1.b.1) Mutual exchange - there appears to be a relatively high level of member co-ordination and interdependence, as well as, apparent mutual exchanges. These exchanges have occurred in task force committee deployment according to volunteers. Th1s allowed those with special interests in certain program topic areas to help determine the outccme of that segment of the pro-ject. While structured by the leadership, the Sunray work conference did include all those interested - after members pressured that leadership. The leaders were still to determine the conference structure, while all members were allowed planning 1nput. The product of that conference was also the result of a mutual exchange of 1 deas and interests. As part of 1 ts list of 13 priorlties, 3 specifically protected the mutual role of in volvement for existing West End community agencies. It also included provisions for and specifications of, "specialized services" which the community "teams" could draw upon. These included many: of the program areas of member agencles, e.g. "Inpatient services" 
- Char1ty Hospital, "children's resident1al care" - Children's: Home, but did not specify the contract agencies.

C.1.c. Unit goals - there appeared to be commitment to unit goals. (degree to whlch not clear) but, to this point, attainment of those goals required cooperation as lllustrated by the Sunray conference plan which broadly provided for the involvement of most of the concerns of the member agencies.

C.1.d. Resource competition - the coalition was not as jet highly characterized by considerable competition for resources and subBequent group conflict. This could be because the areas of resource competition and allocation were still latent and had not as jet become manifest.

C.1.0. Member profit - since the coalition is the vehicle for member participation and determination of rescurce distribution. they seem generally to be intimately involved in its process, especially in the planning portions which directly concern their agency'B area of interest.

\section{C.2. Costs:}

C.2.a. Differential resource issues - this coalition gives evidence of different: 1ssues demanding different resources. Examples include Mr. Y.'s position with the state as providing him with the key resource of assembling the coalitional participants. Dr. S. and Mr. G.'s resource of program area familiarity and prior acceptance by old "steering committee" members greatIJ enabled them to secure the central formal leadership positions of 
the coalition. The issue of who was to attend the Sunray conference was by no means a situation that control of the formal coalitional structure could determine; it required full involvement. of all the community agencies with their respective crucial proGram resources. Subsequently, the conference was opened to all coalition members.

C.2.b. Costs incurred - some of the costs incurred by this coalition include "Information," controlled by old" "steering committee" members; "Intergame," need to approach the County about 1ssue of flscal agent; "division of pay-offs," (somewhat potential) inclusion of provisions in proposal for services provided by coalition members; "dissonance," inclusion of all members in planning conference; and "pressure of time," October 1, deadline and other future deadines.

c.2.c. Principles - certain "decision cost" principles seem to have been operative in this group. "Size" is a factor to the extent that the "minimum winning" member number is large, because of the requirements of the proposal. This large number of required participants, because of their crucial resources, seems to have demanded relative "unanimity" of group members. This also has meaning for an "Indispensable member," since so many: agency resources are crucial, e.g. "old steering committee" knowledge and cruclal lialson, Charity Hospital control of only viable inpatient facility, etc.

\section{C.3. S1tuations:}


C.3.2. Resource independence of powerful - in this coalition:

the weakness and strength of most members is relative to the situation at hand. The tendency seems to have been for the agencies to be most influencial in areas of their own interest. So the outcome was essentially one of exchange among relatively equal members, by each having considerable control over their interest area through task force committees. In the instance of who was to participate in the Sunray conference, the leaders had control of arranging the conference and determining attendance. The reaction of the other coalition members, holding key program resources, forced reconsideration and eventual inclusion of them.

C.3.b. Resource control by powerful - alternative rescurces were scught by the members who did not hold formal leadership positions by going outside of that group, in essence, and mutualiy sought to change a tentative attendance decision for the conference.

D. Analytical questions: because of the extremely large number of participants (approximately 50), the participants will be referred to in more collective terms unless the issue specifically inrolved a limited number of 1dentiflable acotrs. The main categorles will be "old steering committee and "agency representatives."

\section{D.1. Power Resources:}


Crucial liaison with funding agents

Know ledge of proposal requirements

Control of formal coalitional positions

Officlal standing of leadersh1p and authority on a broad community or governmental

Votes base

Relative neutrality in possible agency funding

Previous experience with project
Cruclal proposal component resources, e.s. (1) staff, (2) fac1lities, (3) programs, Examples of $(1),(2)$, and (3) include professional personnel, knowledgable citizens, hospltal, residential care facilities, homemaker prosrams, community participation functions, etc. votes.

D.2. Main coalition decision issues and relevant resources:

MAIN ISSUES

1. Need to coalesce main West End community resource agencies.

2. Whether to proceed on a coordinated basis on a proposal.

3. Assurance of agency cooperation and influence on proposal.

4. "Old steering committee" seeking to control coalition leadership.

5. Corlition's need for formal leadership.

6. Need for proposal planning and initial organizational structure
RELEVANT RESCURCES

Prestige sufficient to assure a response from key community resource representatives.

Liaison with funding agents, knowledge of proposal requirements, crucial proposal component resources, votes.

Crucial proposal component resources, liaison with funding agents, knowledge of proposal requirements.

Lla1scn with funding agents, knowledge of proposal requirements, relative neutrality in possible agency fundire, previcus experlence with project, votes. Liaison with funding agents, knowleage of proposal requirements, relative neutrality in possibly agency funding, previous experience with project, votes.

Knowledge of proposal requirements, relative neutrality,. previous experlence with project, control of formal organizational positions. 


\author{
7. Need to staff \\ "task force" \\ comm1ttees. \\ 8. Whether to in- \\ clude P. district. \\ 9. Need to develop \\ effective com- \\ munity participation. \\ 10. Attendance at cru- \\ clal planning con- \\ ference.
}

11. Control of conference
Cruclal proposal component resources, control of formal organizational positions.

Cruclal proposal c cmponent resources, knowledge of proposal requit remerts.

Cruclal proposal component resources (citizen participation), knowledge of proposal requirements.

Cruclal liaison with funding agents, knowledge of proposal requirements, control of formal coalitional positions, relative neutrality, previous experience with project, cruclal proposal component resources. Control of formel coalitional positions

Decision issues $12-14$ were products of the planning conference.

12. Goals and operational principles.

13. Organizational structure (Board, committees, fiscal agent, staff, Mental Health Toam, additional serv1ces).

14. Community involvement.

15. Need for expended leadership of coalltion.
Know ledge of proposal requirements, relative neutrality, previous experience with project, crucial proposal component resources, votes.

Same as number 12.
Crucial proposal component resources (citizen participation), knowledge of proposal requirements.

Knowledge and control of the coalition's crucial proposal components. (new resource).

D.3. Influencer (s) and influencee (s): DECISION ISSUE

1. Need to coalesce main West End community resource agencles.
INFLUENCER(S)

"Old steering committee"
INFLUENCEE(S)

Main West End community resource agencies 
2. Whether to proceed on a coordinated basis on: a proposal.

3. Assurance of agency cooperation and influence on proposal.

4. "ola steering committee" seeking to control coalition leadership.

5. Coalition need for formal leadership.

6. Need for proposal planning and initial organizational structure.

7. Need to staff "task force" committees.

8. Whether to include P. district.

9. Need to develop effective community participation.

10. Attendance at cruc1al planning conference.

11: Control of conference

12. Goals and operational principles.

13. Organizational structure (Board, committees, , fiscal agent, staff, Mental Health Team, additional services).

14. Community involvement. Ne1ghborhood po- Rest of coalition verty programs and residents Agencies
Community resource agenc1es

Agencies

Coalition:

Agencies

"Old steering Agencies

"Old steering Agencies committee"

(especially c. and $v .-c$.

Individual agencies "old steering committes"(esp. c. and $v .-c$.

Individual agen- Rest of Coalition cles with interests in $P$. (Inferred)

Nelghborhood Coalition poverty program

"Old steering commit tee"

Agencies and residents

Agencles and res1dents

"old steering committee"

"Old steering committee"

Coal1tion

Coalition

Agencies
Not given in casestudy

(2) 
15. Need for expanded leadership of coalition.
Not given in casestudy but inferred::

Hew leaders (committee chairmen)

old leaders
Rest of cosl1tion.

Rest of coal1tion.

D.4. Decision issues and relevant member resources: DECISICN ISSUES

1. Need to coalesce main West End community resource agencies.

2. Whether to proceed on a coordinated basis on a proposal

3. Assurance of agency cooperation and influence on proposal.

4. "Old steering committee" seeking to control coalition leadership.

5. Coalition's need for formal leadership.

6. Need for proposal planning and initial organizational structure. RELEVANT MEMBER RESCURCES

\section{"Old steering committee" \\ "Old steering commlttee"}

\section{Community} resource agencies "Old steering committee"

Individual agencies "Old steering committee"

"Old steering committee"

"Cld steering committee" (esp. $\nabla$. and v. $\left.-c_{.}\right)$
Standing of leadership and authority. on governmental base. Liaison with funding agents, Knowledge of proposal requirements, votes.

Crucial proposal component resources, votes. Lialson w1th funding agents, Knowledge of proposal requirements. Cruclal proposal component resources. Lialson with funding agents, knowledge of proposal requirements,: relative neutrality: in possible agency. funding,. previous experlence with project. Same as number 4 .

Knowledge of proposal requirements, relative neutrality. previous experience with project, control of formal organizational positions. 
7. Need to staff

"task force"

committees.

8. Whether to include P. district.

9. Need to develop effective community participation.

10. Attendance at cruclal planning conference.

11. Control of conference

12. Goals and operational principles.

13. Organizational structure.

14. Community involvement

15. Need for expanded leadership of coal1tion
Individual

agencies

"Old

steering committee" (esp. c. and

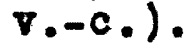

Individual agencies with interests in $P$. "Old steer- Knowledge of proposal ing committee". requirements.

Nelghborhood Crucial proposal compoverty program

"Old steering committee"

"Old steering committee," (esp. $c$. and $v_{.-c .)}$

"old steering committee"

Afencies

Same as number 12 . ponent resource (c1tizen participation).

Knowledge of proposal requirements, crucial liaison with funding agents, control of formal coalitional positions, relative neutrality, : previous experience with project, cruc1al proposal component resources. Control of formal coalitional positions.

Knowledge of proposal requirements, relative neutrality, : previous experience with project, votes. Crucial proposal component resources.

Neighborhood poverty programs (2) and res1dents

Agencies
Existing leaders and main: existing committee chairmen

Crucial proposal ccmponert resources (c1t1zen participation), knowledge of proposal requirements, rotes. Sounter resources of control of component resources, and votes. Knowledge and control of the coalitions proposed components. 


\section{D.5. Qutcome:}

\section{DECISICN ISSUE}

1. Need to corlesce main West End community resource agencies.

2. Whether to proceed on a coordinated basis on

a proposal.

3. Assurance of agency cooperation and influence on proposal.

4. "Old steering committee" seeking to control coalition leadership.

5. Coalition's need for formal leadership.

6. Need for proposal planning and initial organizaticnal structure.

7. Need to staff "task force" committees.

8. Whether to include P. district.

9. Need to develop effective community participation.

10. Attendance at cruclal planning conference.

11. Control of conference.

12. Goals and operational principles.

13. Organizational structure.
DECISION CHCICE

Calling of meeting by Mr. $Y$. of State M.H. Dept.

Proceed on a coordinated proposal.

Each agency to send one or two representatives.

Pre-select Dr. S. chairman and

Mr. G. vice-chairman.

Dr. S. and Mr. G. nominated and elected same as in number 4. Acceptance of Dr. S. and Mr. G. 's plan of procedure, Dr. $S$.'s proposal model, and Nir. G. 's organlzational format (task force committees).

Volunteers from agency representatives to committees relevant to their knowledge and, above $a 11$, interest. Inclusion of $P$. district.

Acceptance and appointment of an ad hoc committee to study (made up of citizen participation or 1ented program representatives). All members of coalition and residents.

"Old steering ccmittee" members to lead discussion groups, chairman to determine agenda and tasks. Approval of same, including 3 (numbers $1,7,8$ ) which spec1f1cally involve serving the interests of the existing agencies. Creation of: a board made up of $1 / 3$ residents, $1 / 3$ agency people, $1 / 3$ "community-at-large;" standing operating committees; fiscal asent (non-profit corporation or the County); executive staff; neighborhood mental health team (at least one psychiatrist, plus 
14. Community involvement.

15. Need for expanded leadership of coalition. other professicnals and paraprofessionals, additional spe-cialized and extended services including many directly related to functions of coalition agencies, e.g. inpatient facility, residentlal treatment, alcohoI1c treatment, etc.). $1 / 3$ of board members (not control), a "Community Review Committee" - advisory only.

steering Committee formed from Old Executive Committee (Dr. S. Mr. G., Mr. Q., sec.) and "Team" Committee chairman Mr. $\mathbf{E}$., Management Committee chairman Mr. T., and two poverty program personnel, one being chairman of Community Review Committee Mrs. I.

D.6. Member Position on Issues and Actual Outcome: $+=$ in favor,

- = against, $?=$ not known

1. Cailing of meeting by Mr. Y. of State M.H.

? (unanimity inferred + ) Dept.

2. Proceed on a coordinated proposal

3. Each agency to send one $?$ (unanimity inferred + ) or two representatives

4. Pre-select Dr. S. chair- ? (unanimity inferred +) man and Mr. G. vice-chair- "Old steering committee" members man

5. Dr. S. and Mr. G. nom1- ? (unanimity inferred +) nated and elected the same as in number 4.

6. Acceptance of Dr. S. and ? (unanimity inferred +) Mr. G.'s plan of procedure, Dr. S.'s proposal model,. and Mr. G.'s organizational format (task force committees).

7. Volunteers from agency ? (unanimity inferred +) representatives to committees relevant to their knowledge and, above all, interest. 
8. Inciusion of $P$. alstrict.

9. Acceptance and appointment of an ad hoc committee to study effective community partic1pation (made up of citizen participation oriented program representatives).

10. All members of coaIition and residents

11. "Old steering committeen members to lead discussion groups, chalrman to determine agenda and tasks.

12. Approval of goals and operational principles.

13. Approval of organlzational structure

14. Approval of plan for cormunity involvement.

15. Expansicn of executive committee
2. (unanimity inferred +)

? (unanimity inferred +)

- "Ola steering committee"

+ Agencies and residents

? (unanimity inferred +)

"QId steering committee" members

8 (unanimity inferred +)

2 (unanimity inferred +)

? (unanimity inferred, after compromise + )

?. Unanimity inferred +)

The three most controversial and significant decisions had not as jet been made by the coalition: (1) specific fiscal agent, (2) specific inltial services, and (3) specific service subcontractors.

D.7. Member Goals Compared With Final Cutcome:

MEMBER

"Old steering committee"

GOALS

FINAL OUTCOME

Development and funding of an innovative community mental health plan
Final outcome of this coalition was not as jet attained. It had completed an 


\section{Agenc1es}

for West End of Metropolitan Area. Protection and promotion of own agency interest and domain. including provisions for funding for these agencies, inc luding, accoraing to individual agency interest, residential treat. ment, alcohollc treatment, inpatient care, etc. overall outline for an innovative community mental health plan for West End Metropolitan Area, with provisions covering and promoting essentially aIl of the member agency interests.

II. Decision-Making Process Analys 1s: In order to assess the casestudy in relation to typologlcal and phase issues' assertions, each main decision (using above sequential numbers) will be placed in a table and discussed later.

\section{PRCBIEM SCLUTION:}

\begin{tabular}{|c|c|c|c|c|c|c|c|}
\hline \multirow{2}{*}{\multicolumn{2}{|c|}{$\begin{array}{l}\text { blem } \\
\text { uation Information }\end{array}$}} & \multicolumn{2}{|c|}{ ROUTINE } & \multicolumn{2}{|c|}{ INCREMENTAL } & \multicolumn{2}{|c|}{ INNQVATIVE } \\
\hline & & Edequate & Inedequate & adequate & inadequate & idequate & Inadequate \\
\hline \multirow{2}{*}{ tine } & adequate & & & $7,5,12,13,14$ & & & \\
\hline & Inadequate & & & & & & \\
\hline \multirow[t]{4}{*}{ emental } & adequate & $6,8,9$ & & 3.10 & & 4,15 & \\
\hline & Inadequate & & & & & & \\
\hline & adequate & & & & & 1.2 & \\
\hline & Inadequate & & & & & & \\
\hline
\end{tabular}

EXPLANATION:

1. The "old steering committee's" assessment of the situation as requiring an unprecedented move (innovative) of calling together all West End community mental health resources seemed to be an 
adequate solution response to the situation.

2. The assessment of the situation as warranting a coordinated effort (given the level of agency interdependency) justified their affirmation of that solution. This situation and solution were very innovative for the social service agencies involved.

3. The realization of the need to assure coalition member cooperation and influence seemed to be a reasonable outgrowth (1ncremental) and assessment (adequate) of the situation. The decision to send representatives was also a reasonable decision and an accurate assessment.

4. The desire of the "old steering committee" to develop a plan to maintain leadership was an adaptation to the expansion of the coalition and an accurate realization from their perspective. The decision to apparently pre-plan the election was an innovative response to this situation and demonstrates a clear analyois of the group and the probability that their solution would be successful.

5. The coalition's recognition of a need for formal leadership was a procedural consequence (routine) of the need to orgenize the new coalition. The solution of electing the handpicked "old steering committee" members was a logical solution and outcome; because of the new members' own lack of experience, 11a1son, etc. The1r understanding of how the election was man1pulated was apparently non-existent. 
6. The coalition's realization of a need for a plan for procedure was a result (incremental) of their seeking to develop a proposal. Their response of deferring to the "old steering committee" plans had become somewhat routinized at this point, and reasonably so.

7. The recognition of the need to staff the committees, which were part of the plan accepted in decision 6 , seemed routine and accurate. The decision to allow those to join the committees which they were "Interested" and knowledgable in seemed to be an adaptive and adequate response to the problem situation of needing to 1111 the positions and having people of matching interests in the group (also a good way to assure the sallency of the project to coalition members).

8. The fact that the $P$. district had not been automatically included in the project area, indicates that the problem of whe-.. ther to include it was an outgrowth (incremental) of the effort: to be comprehensive geographically, as well as, program wise. The recognition of the need to respond seemed to be accurate. The decision to include the $P$. district appears to be routine in view of the inclusion of other areas. This seemed to be an adequate analgsis.

9. The information about the requirement of citizen participation: was a result (incremental) of the coalltion's application for federal funding (including their regulations), as well as, internal pressures. The establishment of an ad hoc committee seemed to be a routine response for this coslition, which already had es- 
tablished this method as its basic procedural approach. The inclusion of citizen participation oriented committee members seemed reasonable.

10. The problem of hom to include at the "crucial planning conference" was a consequence (incremental) of the expanded agency involvement and influence. The coalition leaders did not recognize this; the agency members did. The final decision to include all coalltion members was a reasonable way of adapting (incremental) to the new situation.

11. The situation of determining the leadership for the planning conference was a routine matter of having decided to hold the session, and there seems to be recognition of this. The deferrence to the "old steering committee" (especially the coalition's executive leaders) was a routinized sclution for the coalition by now. This seemed a reasonable reaction.

12-14. Having entered a community planning and federal proposal writing project, there are certain routine, rational procedures which are required. The establishment of goals and operational principles, organizational structure, and community involvement provisions are routine procedures, while the manner and content of how this coalition solved these requirements was highly adaptive (incremental) to its peculiar organizational composition and its network of interests. Their observations and solutions seemed quite adequate and accurate.

15. The need for expanded leadershlp was an outgrowth (incremen- 
tal) of the increased complexity of the project components and the division of labor. This was recognized in raising the issue of the need to expand the leadership. The decision to do so mlght seem incremental, but it was more probably incremental in: view of the "old steering committee's" here-to-fore monopoly of formal coalitional leadership and the impact this could bring to the leadership of the group. The solution does seem to be a reasonable response to the demands of the changed situation.

\section{A. Typological Issues:}

A.1. Problem familiarity - the categories seemed to be helpful. There did seem to be an applicablilty of the decision types, without being overly arbitrary.

A.2. Patterns - seven out of the fifteen main decision issues had identical problem situation and solution tjpes.

A.3. Informational adequacy - the applicability of the variable of adequacy of information seemed to be limited, because it was never really critically employed in analyzing this casestudy.

\section{B. Phase Issues:}

B.1. Innovation - there were only two instances out of fifteen main decision issues in which both the problem situation and problem solution were innovative. There were additional issues which had incremental situations and innovative solutions.

B.2. Diversity - the first two of the fifteen problem situations and solutions were both innovative, and after them both incre-- 
mentel and routine (mixed) orientations entered into the process. These later instances did apparently occur in a random fashion from incremental, routine, and even innovative (solutions only);. There were, after the first two innovative - innovative areas, two incremental - incremental, one routine - routine, three incremental (situation) - routine (solution), five routine incremental, and two incremental - innovative.

B.3. Rational phases - there seems to have been a general use and rellance upon rationality in decision-making in this casestudy, eventhough self interest was clearly operative. A tracIng of the stages or phases of a rational process model in this casestudy in an overall perspective could include:

(1) Issue or problem identification: need for improvement of community mental heaith through an innovative, comprehensive neighborhood program.

(2) Information gathering: assignment of "task force" committeos.

(3) Listing of alternative strategles and solutions,

(4) Determination of consequerces,

(5) Comparative evalutation, and

(6) Cholce of strategy or solution: the "crucial planning conference" allowed for this process.

(7) Enactment of strategy and solution - not to date of case-study.

It should be noted that many individual decisions could be assessed in a similar format of the rational phase model. 
B.3.a. Relative applicability - this coalition was marked by a hlgh degree of cooperation and consensus, with definite instances of bargalning and exchange. It also used a rational process method.

B.4. Unit bies - unit biases were very much in evidence in this coalition from the pattern of volunteers for the "task force" commitiees relevant to a unit's interests to the interest laden: proposal, model, which resulted from the planning conference. An: 1llustration is the strong role taken by the citizen based poverty programs to be the chief advocates for citizen participation.

B.5. Coalitional cohesiveress - this coalition had members who had issue and interest differences and disagreements (relatively mild), but this did not preclude the possibility of forming a workable and working coalition.

Critique: The usefulness and applicability of the decisional method seemed to be of relatively lessened value, largely because of the lack of more specific casestudy date on allignment of members on 1ssues, and the fact that the coalition had not as yet Plnalized 1ts work.

A more specific criticism concerns assertion I.B.2.a., which malntains that formal coalitional roles carry little real power. The casestudy material indicates that the coalitional leadership positions of the "old steering committee" members were instruments of considerable influence. The coalitional "task force" committee chalrmen also had considerable impact on the planning 
process and this eventually assured them positions on the executive committee.

Another criticism is of assertion C.1.C., which maintains that the higher the commitment to individual unit goals,, the less the cooperation. The casestudy implies a definite commitment. by units to their goals, but cooperation did take place because of unit interdependence. This possibly indicates that interdependence may preclude at least.blatant pursulti of self interest. Another possible motive for this degree of apparent cooperation: could have been for external goals of coalition members. Being a member of the coalition in itself could have been a resourco sought among other possible goals; e.8. enhancement of resources in another coalition or in the eyes of constituents.

While assertion II.A.2, maintains that problem situation: and solution types are usually identical, the data from the casestudy revealed that only 6 out of 15 of the decision issues were of this type. Subsequently, they were not the usual case. The variable of information adequacy II.A.3. was of little use in: this casestudy. This, however, may be more attributable to the lack of casestudy data than to a defect in the model. 


\section{CHAPTER 5 \\ Summary of Casestudy \\ "Project Rap"}

This coalltion was developed by representatives of social service agencies around the issue of establishing a preventive program for pre-allenated youth in a metropolitan area. The coalition arose from the merger of two previously separate attempts in the area. One was an attempt by a drop in center for allenated youth through the public schools (which rejected the proposal). The second group was initiated by Family Service. Agency A., which involved three other Family Service agencies. This group then asked the Drop in Center representative to meet: with them and later was asked to join the group.

The coalition eventually decided upon a focus for a proposal to the school system for setting up a preventive program for pre-alienated youth. The decision was made to divide the responsibility accordine to member interest: Drop in Center was to focus on drop in centers for youth and Family Service agencies on drop in centers for the parents. Inltially, some concern about the consequences upon community support by including the controversial drop in center member was expressed by the Family Service members. However, it was soon recognized that the Family. Service Agencies needed the Drop in Center's rapport with youth, and the Drop in Certer needed the Family Service Agencies' rapport with other "established" agencies and their public image of respectablilty in order for the program to work.

The proposed plan was accepted by the coalition after each member's respective "parent organization" approved 1t. Family 
Service Agency A. chaired the group and the Drop in center re-presentative largely wrote the proposal with assistance from a member of Agency A.

The proposal was rejected by the school board which was at the time facing a bond election, and whose superintendant was under public criticism for his proposed reorganization of the school district. One criticism raised by the board was the fallure to involve school counselors in the project.

The coalition developed a six week, summer pilot project through the park department, which they decided was a fallure because of 1 ts poor location and shortness of time.

The coalition then infliated an intensive lobbying effort with school board members. The controversial representative from. the Drop in Center did not participate in this effort in order to avold further his alienating of the school board members. Shortly after this, the proposal was resubmitted and was accepted by the board.

This was followed with the coalition's establishment of a decision-making executive board and an implementing project coordinator.

The members of the coalition felt that generally the group was cooperative. There was considerable discrepancy among resource contributions of the members. The Family Service Agency A., one of the other Family Service Agencies, and the Drop in Genter contributed the most. The only area of internal conflict. arose over the type of publicity and image given the project once 1t was under way. The Drop in Center representative and several 
other coalition members felt the focus had been switched from education and prevention to problem cases. The contention was raised that this was a consequence of shifting program authorIty away from the professional agency staff to lay executive board members. This is challenged by the fact that the executive board members were the same people involved in the or 1Binal planning committee.

\section{CASESTUDY ANALYSIS}

$$
\text { "Project Rap" }
$$

\section{Decision-Making Power Analysis:}

A. Theoret1cal Issues: This casestudy can be analyzed with reference to the internal and external positions of each of 1 ts members. This is especially evident in the external and internal structural issues of this coalition. The assessment of dec1sional dynamics also is significant and the nature of "exchange" appears to be directly influenced by the structural 18sues of this case.

\section{B. Structural Issues:}

\section{B.1. Externa1}

B.1.a. Domain - both initial proposals (Drop in Center [Mr. A.] and the agency sponsored one) were concerned with expanding program domains into the area of "pre-alienated youth."

B.1.a.1) Resource interdependence - the internal resources of each of the two proposal groups was regarded to be inadequate without the inclusion of the other. The established agencies 
needed the Drop in Center's (Mr. A.'s) rapport with alienated youth, staff time, and funds. The Drop in Center needed the agency resources of public respectability, staff time, and funds.

B.1.a.2) Member autonomy - the coalition does not seem to have restricted the usual operations of 1 ts members. The coaliton Itself utilized very limited internal and external resources and had no real organizational sanctions upon 1ts members.

B.1.b. Extra-coalitional relations - a considerable degree of the Influence exercised by the Drop in Center upon other coalition members was based upon 1 ts extra-coaliticnal relations with the metropolitan allenated youth. On the other hand, the established agencies based much of their influence in coaliticnal actirIty upon their extra-coalitional relations with the "established" community and as being a "respected" member of the community.

B.1.c. Unit interests - membership in the coalition does not appear to pose a threat to any existing interests and inter-organ1zational relations of its members. There is reference to some Initial degree of concern by the established family service agency members about including a ccntroversial program such as Drop in Center as a member. This was based upon the fear of losing community support from such an alliance.

\section{B.2. Internal:}

B.2.a. Formal roles - there did not appear to be considerable influence vested in formal coalitional roles. The real power seemed to reside in resource control and use. There was some influence 
In that Family Service Agency A. controlled the position of chairman and was intimately concerned about the formation and direction of the project. The Drop in Center was also responsible for drafting the proposal.With some assistance from Agency A.

B.2.b. Representativeness - the members Involved appeared to be without internal conficts with respect to accurately representing the over all interests of their "parent organizations" Im this project.

B.2.c. Consensus - while this case is generally characterized by group consensus and cooperation, there developed a recognttion of degrees of influence among coalition members.

B.2.c.1) Differentlal power - - In the issue area of having contact with the client populations (preallenated jouth and their. parents), there was a recognition that Drop in Center had more influence with the former group and the family service agencies with the latter. In addition, the family service agencies clearlyi emerged as more influential overall by their capability of dealing with crucial external organizaticns (school board).

B.2.c.2) Testing - there was an early testing of member power and influence in the coalition around the issues of mutual dependence and resource capabilities in the main areas of decision influencing (B.2.c.1).

B.2.d. and e. Single or multiple leadership - the coalition is composed of several leaders of ccnsiderable internal influence, 
but the service agency grouping tends to be more frequently influential and dominant. The distribution of power appears to be: balanced with respect to internal issues and influence and Imbalanced with respect to external issues and influence. Drop in: Center and the agencies are balanced in the former, and the agencles are dominant in the latter.

\section{Exchange Issues::}

\section{C.1. Conditions:}

C.1.2. Resource generality - all of the coalition's members shared the general resources of staff time and money. While these were committed with varying degrees by the coalition's members, they were at leasti potential resources for exchange. snother common resource was organizational endorsement. The more spec1fic resources included community respectability and interagency contact by the service agencies and youth rapport by Drop in Center.

C.1.b. Resource dependency - the casestudy indicates that coal1tion members clearly and openly recognized their position of interdependence for resources needed for goal attainment. At the second meeting of the agency group, the casestudy notes "1t was agreed that none of the agencies could provide an outreach pro-. gram on 1ts own, because of a lack of funds and staff." It was notes that later when Drop in Center became involved in the coal1tion; that it became apparent that it was identified with "drug users" and "street people." Furthermore, the family service a- 
gencies were ldentified as part of the "establishment" by young. people. The consequence was that these other coalition members had resources which could compensate for each other's deficiencles. The subsequent division of labor in their proposal indicates the result of bargaining: Drop in Center was respons1ble for youth drop in centers and the famlly agencles for a parents' drop in center.

c.1.b.1) Mutual exchange - the high degree of co-ordination and interdependence of the units seems to have been manifested in. the mutuality of the exchange in the planning phase. However, when resources were actually committed only three of the coali-. tion members contributed in any substantial way.

C.1.c. Unit goals - the goal of the coalition seems to have beem directly related to the different units' main areas of concern, jet were an expansion of them. Furthermore, the two main: factions, Drop in Center and the Family Service Agencies, sought to promote their areas of special interest within the broader coal1-. tional goel. This, however, did not result in a situation of low cooperation. Actually, there was a high degree of compatibility, contrary to assertion C.1.C.

c.1.d. Resource competition - this coalition was not characterized by competition for resources, nor group conflict.

C.1.e. Member profit - there was definitely a discrepancy in degrees of involvement among scme of the coalition's members, and this was directly related to the amount of resources contributed 
by each member. Those who contributed more resources in this case, also gained more resources in that their staff were able to utilize public school facilities, as well as, the complementary resources (including reputations) of the other more active members. The members which also were active in leadership also contributed and shared in more of the benefits gained.

\section{C.2. Costs:}

C.2.a. Differentlal resource 1ssues - this casestudy demonstrates how different issues often require different types of resources. The internal planning process reveals how the two main segments of the coalition utilized their special resources to obtain their particular goal's approval in the proposal. Drop in Center had the resource of rapport with youth and got a jouth drop in center accepted. Famlly service agencies had the resource of community respectability and hed an adult drop in center included in the proposal. They all had the common rescurces mentioned in. c.1.b. In addition, the family service agencies lobbled the school board due to their good contacts with "established" agencles, while Drop in Center's Mr. A. temporarily dropped Irom: activity.

C.2.b. Costs 1ncurred - the group members incurred the "division of pay-offs" costs after the program had been divided up between Drop in Center and the service agencies and later when the program actualiy began. "Responsibility" costs were incurred by the Executive Board of "Rap" for their controversial publicity program. "Intergame" and "persuasion" costs resulted from the co- 
alition's lobbying of the school board members.

C.2.c. Principles - functioning as a consensus type of group the "unanimity principle" seemed to be operative in attempting to maintain a moderate process. Drop in Center was an "1ndispensable member " to the service agencies and vice versa. As an external unit, the school board was clearly an "Indispensable member." While the school board did not particlpate (nor was requested to do so) in the on-going coalitional process, its dec1sion ultimately determined the fate of the group's program and goal. In this sense, the board' s vote of approval was "Indispensable."

\section{c.3. S1tuations:}

C.3.2. Resource Independence of powerful - there are perhaps two apparent incidents of the more powerful not needine the resources of the weaker, and where the weaker employed other commodities for exchange. In the first example, the school board did not belleve it needed the resources of the coalltion (it was a threat), but the coalition changed 1 ts tactics and used their resource commodity of good public contacts and persuasion to achieve their goal. Another illustration is when Drop in Center's Mr. A. felt himself to be unable to deal with the school board, he reduced his status in front of the other members. Possibly to counteract this, Mr. A. raised the 1ssue about publicity to regain a role of infiuence as an indispensable manager of how the work should be done. 
C.3.b. Rescurce control by powerful - in this casestudy, the coalition remalned within the process of attaining resources from stronger (school board) or essentially equal (active coalltion members) units. One example of seeking alternate resources was the establishment of a summer program utilizing park department facilities after their proposal was first rejected by the school board.

D. Analytical Questions:

D.1. Power resources:

DROP IN CENTER

Staff time
Funds
Rapport w1th
Jouth
Vote(s)

Staff time

Rapport w1th

$\operatorname{vote}(s)$
FAMIIY SERVICE AGENCIES

Staff time

Funds

Rapport with established agencies

Image of respectability

Votes

D.2. Ma1n coalition decision issues and relevent resources:

MAIN ISSUES

1. Project goal

and focus

2. Acceptance of proposal

3. Presentation of plan to school board (extra-coalitional decision)

4. Sumer program

5. Presentation of plan to school boerd (extra-coalitional decision).
RELEVANT RESCURCES

Votes, staff time, funds, rapport with' Jouth, Image of respectability.

Votes and resources relevant to the plans make-up (not given in casestudy).

Respectable Image, Inclusion of school board, information, staff time, funds, promote public image of 8 chools rap.port with schools.

Votes, fac1lity, staff, funds.

Respectable image, inclusion of board, information, promote public image of schools, rapport with schools. 
6. Program

structure
Votes, maintenance of coalition member in-put (resource and policy).

D.3. Influencer(s) and Influencee(s): DECISICN ISSUE INFLUENCER(S) INFLUENCEE(S)

1. Project goal

Drop in Center Agencies Agencies Drop in Center

2. Acceptance of proposal

3. Presentation to school board

Not given in casestudy

4. Summer program

Coalition School board

Not given in casestudy

5. Presentation to school board

Coalition(agency school board members only)

6. Program

struc ture

Not given in casestudy

D.4: Decision 1ssues and relevant member resources:

DECISICN ISSUES

1. Project goal

2. Acceptance of proposal

3. Presentation to school board

4. Summer Program
RELEVANT MEMBER RESCURCES

Drop in Center Vote, funds, staff time, rapport w1th youth.

Agenc1es

Votes, funds, staff rapport with established agencies, 1mage of respectability.

Not given in casestudy but above resources (1) would be relevant again.

Coalition

Rapport with schools (partial: exception Drop in Center), funds, staff time.

Not given in casestudy but above resources (1) would be relevant again. 
DECISICN ISSUES

5. Presentation to school board

6. Program

structure
REIEVANT MEMBER RESCURCES

Coalition (agency members only)

Respectable image, staff time, funds, information, inclusion of Boerd, rapport with schools.

Not given in casestudy but votes and maintenance of coalition member in-put (resource and policy).

\section{D.5. Outcome:}

DECISICN ISSUE

1. Project goal

2. Acceptance of proposel

3. Presentation to school board

4. Summer program

5. Presentation to school board

6. Program structure

\section{DECISION CHOICE}

Formation of arop in centers for pre-alienated youth and drop in centers for their parents.

Affirmative - drop in center plan.

Rejected

Affirmative - park department fac1l1ty and coalition staff and funds.

Affirmative - drop in center plan through the schools.

Decision-making executive board and a project coordinator.

D.6. Member Position on Issues and Actual Outcome: $+=$ in: favor."

- = against, ? = not known.

\section{DECISICN CHOICE}

1. Formation of drop

in center plan

2. Affimation of plan

3. Rejection by school board

MEMBER POSITICN

Drop in

Center

Agenc1es

$?$

Coalition

Sphool board: + 
4. Affirmation of sum-

5. Affirmation by school board of plan for drop. in centers

\section{Executive} board and project coordinator
Coalition

School board

$?$ (unanimity inferred +)

\section{D.7. Member Goals Compared With Final Cutccme:}

\section{MENBER}

Drop in center

Agencies

\section{GOALS}

Formation of drop in centers in high schools for "pre-allenated" jouth with an educational

focus.
FIMAL OUTCCME

Formation of drop in centers in highschools for (apparentiy) "prealienated" youth and their parents with a focus on problems.

Pormation of arop in centers in high schools for families of "preallenated" youth with an educational focus (latter point Implied by casestudy).

II. Decision-Making Process Analysis: in order to assess the casestudy in relation to typologlcal and phase 1ssues' assertions,, each main decision (using above sequential numbers) will be placed in a table and discussed later. 
PROBLEV SCLUTICN

\begin{tabular}{|c|c|c|c|c|c|c|c|}
\hline \multirow[b]{2}{*}{$\begin{array}{l}\text { blem } \\
\text { uation }\end{array}$} & \multirow[b]{2}{*}{ Information } & RCUTINE & & $=\frac{1}{\mathrm{NCR} N \mathrm{NE}}$ & TAIL & \multicolumn{2}{|c|}{ InnovatIve } \\
\hline & & adequate & Inadequate & adequate & Inadequate & adequate & Inadequate \\
\hline & adequate & & & & & & \\
\hline tine & inadequate & & & & & & \\
\hline remental & adequate & & 6 & 2.5 & & & $4 !$ \\
\hline & Inadequate & & & & & & \\
\hline jorative & adequate & & & & & 1 & \\
\hline & Inadequate & & & 3 & & & \\
\hline
\end{tabular}

\section{EXPLANATICN:}

1. The problem of dealing with, and providing social service for, "pre-alienated" jouth and their families was a new area for all coalition members. The proposed solution, a plan for arop-in centers in high schools for this segment of the population, was an untried method in this area. Their overall information appeared to be edequate.

2. The problem of deciding on the written proposal was a natural outgrowth (1ncremental) of the overall group process. The solution was also an outcome (incremental) of an earlier consensus about the coalition's goal. The information seems adequate in: 11ght of the above.

3. For the coalition as a whole, except for Drop in Center which had already submitted a similar plan to the board, the situation of presenting the plan to the school board was a new (Innovative); approach. Their lack of tactics and awareress of dealing with the school bosrd indicates inadequate information and situation assessment on their part. The solution or choice of the board in rejecting the plan was an adaptation (Ancremental) to their 
earlier decision on a similar plan and on adaptation to their political situation. Their information and assessment seems quite accurate and adequate.

4. The rejection of the plan by the board forced the coalition: Into a sltuation of having to adapt (incremental) to their alternatives. This seems to have been a correct (adequate) assessment. The solution of developing a pllot project through the park depurtment and their own resources was a new (innovative) move by the group. The deployment and outcome of that plan was assessed as a fallure, indicating a lack of information in the solution plan they developed.

5. The re-presentation of the plan to the school board, with considerable persuasive ground work, was an adaptation( incremental) of the earlier rejection and reflects an accurate assessment and view (adequate) of the situation. The board's solution of affirmation was a developmental result (incremental) of thelr changed political sltuation (also need for additional resources) and increased understanding (adequate information): of the program.

6. The need to establish a program governing structure is an adap-tation (incremental) to the plan's acceptance and its need for 1mplementation. The coalition seems to have been aware (adequate) of this. The actual composition of the executive board was merely a routine re-naming of the planning group. From the casestudy, several (especially Drop in Center) of the coalition members were not aware (Inadequate) of the consequences of this 
solution upon how the program would actually be conducted (publicity disagreement).

\section{A. Typological Issues:}

A.1. Problem familiarity - the categories of problem situation and solution tend to be applicable and provide greater clarity in analyzing the decisions. A distinction between total coalltion membership and individual members would be helpful.

A.2. Patterns - there appearęd to be no clear relationship between the type of problem situation and solution being the same. Th1s was the case with 3 of the 6 main decisions analyzed.

A.3. Informational adequacy - information adequacy or inadequacy was useful in analyzing the coalition's decisions. This was especially the case in instances of inadequate information (problems $3,4,6$ ), which helped make the process more understandable.

\section{B. Phase Issues:}

B.1. Innovation - only problem 1 was an innovative situation with an Innovative solution. The most common problem situations (problems $2,4,5,6$ ) and problem solutions (problems $2,3,5$ ) were incrementally orlented with numbers 2 and 5 having both an incremental situation and solution.

B.2. Diversity - of the main 1ssues, there was no gravitation toward routine orientations, but incremental orlentations became 
predominant after decision 1 (innovative - innovative).

B.3. Retional ohases - the formation of the coalition seems to hare followed rational phases in decision-making. Both of the principal coalitional segments identified the problem (rational model step 1) as "pre-allenated youth." There was an effort to Bather information (step 2) from those involved about the problem. They then listed two possible alternative strategies and solutions (step 3), parental drop in centers and youth drop in: centers. They determined the consequences of each (step 4), in volve parents und family agencies only or involve youth and Drop in center only. They made a comparative evaluation of the Iindings (Step 5), incomplete alone.. They then selected a solution (step 6 ), combining the two. They finaliy sought to enact the solution by (step 7) presenting. 1t to the school board for approval.

This same process seems also to be evident in the coalltion's decision and process of re-applying to the school board: with an alternative strategy. The decisions based upon inadequate information (problems $3,4,6$ ) indicate a lack of rational decision-making steps. Inadequate situation assessment (dec1810n 3) Indioates poor problem identification (rational step 1). Inadequate solution assessment (problems 4,6) indicates poor soiution planning and enactment (raticnal steps 2-7).

B.3.a. Relative applicability - this coalltion appears to have demonstrated the variables (in certain instances) of rational decision-making and internal cooperation and consensus in goals. 
It should be noted, however, that those decisions which followed the rational model were the result of rational cooperation. In this casestudy the rational process was apparently the independent variable and cooperation the dependent variable. This is indicated by the fact that the coalition's irrational dec1sions (problems $3,4,6$ ) were apparently unanimous decisicns (cooperation and consensus) but did not follow rational decisicnmaking steps. Cooperation does not necessarily cause a coalition to decide raticnaliy. Rationality does apparently necessitate cooperation and consensus.

B.4. Unit bias - unit biases were evident in the decision-making process, especialiy in goal and program setting (decisions 1,2); and the school board votes (decisions 3,5 ).

B.5. Coalitional cohesiveness - this casestudy's coalition was characterized predominantly by issue and interest agreement and consensus with slight variance of main focus between Drop in: Center (youth) and the Family Agencies (family), but these were closely interrelated.

Critique: The analytical model generally was useful in interpreting the casestudy. There were, however, problems with scme specific aspects of the model.

One difficulty arose from the need to analyze the role of the school board in the case. If it is an external unit, it is difficult to assess the transactions between it and coalition within the existing analytical model. The model falls to adequately take into account coalitional relations with extra-coall- 
tional units, especially those crucial to goal attainment. If the Board were to be considered a coalition member, it is difsicuit to rationalize, since it was not involved in internal coalitional operations and policy decisions.

As mentioned above in the analysis of the "Rap" coalition" assertion.I.C.1.C. appears to be contrary to the casestudy flndIngs. There appears to have been a considerable degree of commitment to individual unit goals, as well as, a high level of coalitional cooperation; instead of low cooperation as I.C.1.C. contends would result.

Another model weakness is its inability to account for liabilities, as well as, resources. This issue arises from Drop in Center and the agencies' liabilities. In assessing the first decision of the school board, Drop in Center's controver$81 a 1$ Image was a liab1lity, but the model makes no specific reference to the role of liabilities in analyzing decision-making. An aditional model deficiency develops from its omphasis upon main issues and decisions. This results in biasing a nearly: exclusive analys is of innovative and incremental decisicns. The outcome is a fallure to analytically account for routine declsion situations and solutions: This could be altered with a more detalled casestudy, however, and is not necessarily an inherently model based defect.

Also with respect to decision tjpes, it would be helpful In classifying casestudy decisions if these decisions were anelyzed for the entire coalition as an entity. Otherwise, confusion: In classification could result from decisicns like number 3 , 
where the situation was innovative for the coalition as a whole, but incremental for Drop in Center, which had once before gone that route. A possible deficlency also under "Typological Issues" is found with assertion II.A.2. The findings do not reveal that the matching of the same problem situation and solution types 18 necessarily the general rule.

Assertion II.B.3.a. seems to be inconsistent with the findIngs about the "Rap" coalition. Instead of cooperation determining whether rational decisions are possible, rationality appears to require cooperation in this casestudy. However, the latter is not necessarily valid, since all of the decisions were cooperation and consensus oriented, and no evidence is provided by this case as to whetrer rational decisions occur in conflict. decision processes. 


\section{CHAPTER 6}

\section{Summary and Conclusions}

Having applied the analytical model to four casestudies, an across casestudy assessment of the usefulness and relevancy of that model will be employed to give a broader evaluation and summarization. This will be done through the use of a scaling model applied to each assertion or proposition of the analytical model for each casestudy. Following this will be a summary statement on the findings for each of these assertions.

The terms used for scaling were chosen on the basis of expressing whether the findings were in keeplng with assertions. In numerous assertions, a result contrary to the assertion is possible, so the scaling terms had to account for the possib1lity of that phenomenon. As a result, the basic terms "identical" and "opposite" were selected for scaling purposes. "Identical" refers to the sameness of the assertion, and what was found in the casestudy. "Cpposite" refers to the contrariness of the assertion, and what was found in the casestudy. Both terms will be utilized on a scale increasing in degree from "slightly," to "essentially," to "very." "Ambiguous" will be used as a term intermediate of "1dentical" and "opposite," to express a lack of clarity or certainty about the scaling of a finding.

The assertions will be scaled according to the casestudy Iindings, and this will be foliowed by comments on individual assertions and then on the entire model and study. 
Very $\frac{3}{3}$ dentical Essentially Identical Slightly ${ }_{1}$ dientical Ambiguous S1ghtly Cpposite Essentially Opposite Very Opposite $-2$ $-3$

\section{CASESTUDY FINDINGS}

"Ch1ld "Black "Mental "Project

Assertion AdVocacy" Coalition" Health" Rap" Total Mean

I.A.1.

I.A.2.

I.B. 1.2 .

I.B. 1.0 .1$)$

I.B.1.a.2)

I.B.1. b. . 3

I.B.1.C. 3

I.B.2.2. 2

I.B.2.b. 3

I.B.2.C. 3

I.B.2.c.1) 3

I.B.2.c.2) 2

I.B.2.d. 2

I.B.2.e.

I.C.1.a.

I.C.1.b.

I.C.1.b.1)

I.C.1.c. 3

I.c.1.d. 3

I.C.1.e. 3

I.C.2.2. 3

I.C.2.b. 2

I.C.2.c. 2

I.C.3.a. 2

I.C.3.b.

I.D. 1 .

I.D.2.

I.D. 3 .

I.D. 4 .

I.D.5.

I.D. 6 .

I.D.7.

II.A. 1 .

II.A.2.

II.A.3.

II.B. 1 .

II.B.2.

II.B.3.

II.B.3.a.

II.B. 4 .

II.B. 5

TOTAL
3
3
3
3
3
3
3
1
2
3
3
2
0
2
3
-2
0
3
3
3
3
3
1
2
2
3
3
2
3
3
2
3

3
3
3

3

3

$3 \quad 3$

3

3
-3

-3
0

3

$-1$

2

2

3

3
-3

-3
1
3

3

3

3

2

2

3

3

3

3

3

2

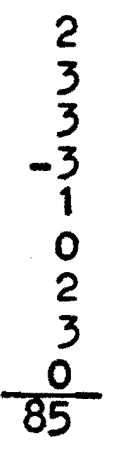

$\begin{array}{ll}12 & 3 \\ 12 & 3\end{array}$

123

123

$10 \quad 2.5$

$11 \quad 2.75$

$11 \quad 2.75$

11.25

$5 \quad 1.25$

$10 \quad 2.5$

$11 \quad 2.75$

$5 \quad 1.25$

$\begin{array}{ll}5 & 1.25\end{array}$

82

$11 \quad 2.75$

$7 \quad 1.75$

$7 \quad 1.75$

00

$7 \quad 1.75$

123

123

$11 \quad 2.75$

82

82

12

123

$10 \quad 2.5$

12

12

7
11

82

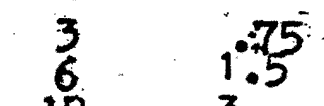

$-3$

1.25

1.75

$6 \quad 1.5$

12
$\frac{5}{330}-\frac{3}{82.25}$ 
"Ch1ld

"Black Advocacy"

MEAN 2.32
Coalition
"Mental "project,

131

$\ldots$

\section{Comments on Casestudy Findings}

I.A.1. The assertion that a positional analys1s would be a viable method of assessing the power and influence of coalition members in: decision-making was very useful in the casestudies reviewed. The data in the casestudies was generally adequate in enabling the effective use of this analytical method. Problems did exist in that there were data gaps because the case studies were not compiled originally for nor according to the needs of, this model.

I.A.2. The assertion advocating that a decisional analysis was a revealing and useful method of assessing coalitional decision-making was basically substantiated in this study. This was especially the instance with "exchange 1ssues" and also w1th the "analytical questions," except that the casestudy data was frequently insufficlent to fully utilize the potential of the andytical questions. The deficlencles: were clearly more in the lack of data than in the questions.

I.B.1.a. Thls assertion was highly substantiated by the findings of th1s study. "Domain" protection and expansion is a significanti coalitional analjtical variable.

1.B.1.a.1) Interdependency as an organizational motive for forming and joining coalitions to promote domain protection or expansion: is a salient dynamic of coalitional behavior.

I.B.1.a.2) The asserticn that the autonomg of coalitional members is relative to the degree of coalitional control of resources and sophistication of internal organization was a useful proposition 
In analyzing the casestudies. The use of the notion of member autonomy should be clarified as referring to member coalitional behavLor - behavior with respect to coalitional activities and concerns.

I.B.1.b. The assertion that the extra-coalitional relations of coalition members can be a source of a considerable amount of their influence withim the coalition is strongly indicated to be the situation: in the four casestudies assessed. Probably, a related assertion would be useful with respect to the extra-coalitional rela tions of the coalition as a unit as being a significant facton in the coalition's degree of influence in achleving its goal or program.

I.B.1.C. The proposition that since coalitions are usually concerned only with issues secondary to each unit's interests, that these unit's primary concern within the coalition w1ll be to protect and promote its primary interests is substantiated in the casestudy mater1a1. Th1s phenomenon was apparent in two forms: (1) curta1lment or abstension from certain or all coalitional operatione whem a conflict between unit and coalitional activities arose and (2) inrolvement in coalltional areas which were specifically relevant to member unit interests.

I.B.2.a. The assertion thatiformal cosiltional roles carry little real power was not clearly substantlated by the casestudy data. It 18 possible that 1t could have increased the external influence of Individual members. At best, the result is amblguous. The scoring system may have added some confusion since 3 of the 4 casestudies rated the assertion as related to the data, but the 1 exception was a. strongly. different result. Since no clear result is apparent, this assertion requires additional testing and perhaps a reassessmente 
of data material.

I.B.2.b. The proposition that member units may only be representIng a segment of lts "parentiorganization" seemed to have only slight value. In Its statement it excludes the possibility of an: opposite finding by use of the word "may." It only asserts that there is the possibility that some unit members may not. fully: represent their "parent organization."

I.B.2.C.1) The assertion that different actors w1ll be more dominantin different 1ssue areas was very well supported by the data. This appears to have a clear relationshlp with the issue of member interdependency - units join together to benefit from the resources of each other. It may also have detrimental effects relative to the weaker unit(s) in certain of these instances. I.B.2.c.2) The assertion that a ccnsiderable amount of testing of one another's power resources will occur, especially early in a coalition's operation was only partially substantiated by the analysis of the casestudies. Th1s 18 somewhat misleading in that 3 out of the 4 cases demonstrated this phenomenon, while one, "Mental Health," revealed a small degree of testing, and this occurred relatively late in the coalition's operations. This group had not as yet entered truly conflictual 1ssues which were to ar1se. Up to the point of when the case was written, it had operated predominantly as a consensus coalition, which seems to have minimized testing. It is also possible that prior external relations amons members made member. power resources known. 
I.B.2.d. The assertion that if a single leader (formal or informal) emerges in a coalition, that this indicates a hierarchical "imbalance" withir the coalition was slightly evident in the casestudy material. This assertion is similar to I.B.2.b., in that it has no opposite, since its conditions are internal, 1.e. when there is a single leader, there is imbalance.

I.B.2.e. The assertion that if there are several coalition ieaders, this indicates a "balanced" distribution of power resources, seemed to be in keeping with the findings. This assertion is like I.B.2.b. and I.B.2.d. in its internal validity, 1.e.. if there are several leaders, this indicates "balanced" power. dssertions I.B.2.d. and I.B.2.e. could be combined in that a coalition's leadershlp will be elther singular or distribu- ted, and this is indicative of imbalanced or balanced control of resources respectively. This should also be assessed separately for formal and informal leadership and resources and then poss1bly together as an overall view of the ccalition's leadership structure. Part of the confusion with the findings for these two propositions was that coalitions cculd have both balanced and Imbalanced leadership and resource distribution depending upon whether the reference point was formal or informal leadership. and resources.

I.C.1.2. The proposition that the more general a resource is, the broader 1ts applicablifty was well supported by the casestudy data. This is somewhat an indisputable assertion, but serves well the function of highlighting a significant varlable 
of power analysis of coalltional behavior.

I.C.2.b.. The proposition that resource dependency fosters coordination and exchange by means of bargalning vas essentially substantiated by the data. There was one marked exception; "Black voalition," which had a high degree of internal conflict. It could be argued that this was essentially an ldeological conflict. which was impervlous to pragmatic resource dependency. Iti was also the case that nelther leading member had resources sufficient. for lts own tasks: thus resulting in a loss of leadership confidence in: each other, which would also undermine supposed dependency. It is also poss1ble that their goal was coordinated by the use of conflict tactics.

I.C.1.b.1) The assertion that the greater the coordination and interdependence, the more relations will take the form of mutual exchange was well supported by the research findings. The only exception was the "Black Coalition" to which assertion: I.C.1.b.1) is noth really relevant, because it was characterized by little coordination and considerable conflict. The "Child Advocacy" case also had elements of conflict and lack of cooperation.

I.C.1.C. The proposition that the greater the commitment to uniti goals, the lower the level of cooperation was not substantiated nor. refuted by the casestudy data. Amblgulty was the outcome. There seems to be a more basic issue involved for which this assertion fails to account. The real issue is whether a unit's goals: are consistent with those of the coalition. If they are, and the uniti is highly committed to its interest, in those goals, then the member w1ll be highly, cooperative, e.8. the "Mental Health Center" and "Project Rap" casestudies. If a unft!s goals 
are contrary to the coalition's goals and the unit is highly committed to its own, ther the member will engage in a low level of cooperation (possibly even conflict).

I.C.1.d. The assertion that the greater the competition for resources, the greater the conflict was substantiated by the casestudy material. This assertion is basically concerned with correlating rescurce competition and conflict, and where they did occur it was relevant, but where they did not, nothing was established nor refuted..

I.C.1.e. The proposition that the greater the relationship between the rescurces avallable through coalltional membership and the unit's goals, the higher the level of the unit's involvement in the coalition was well established by the casestudy data. This exchange assertion is closely related to the external structural 1ssue assertion, I.B.1.a., which deals with domain concerns as prompting unit coalitional membership.

I.C.2.a. The assertion that different issues often require the exercise of different resources is well supported by the casestudy data. This has clear implications for the relative influence among those who control these resources.

I.C.2.b. The proposition that there are different types of costs which can be incurred by a coalitional unit, subgroup, or full coalition (und the types of costs suggested) was well sustained by the casestudy material. Of all of the "cost" types found $1 \mathrm{n}$. the data, three were most common: "responsibility," "Inter-game," 
and "division of pay-offs."

I.C.2.c. The assertion that there are certain "decision cost" princlples which can alter the degree of the cost incurred (size, unanimity, and indispensable member) was substantlated by the analysis of the cases. The frequency of each principle in all four cases was size (1), unanimity (4), and indispensable member (3).

I.C.3.2. The proposition that in cases where the more powerful do not need the resources of the weaker, the potential receptor(s), the weaker, may employ its other resource potentials, including external, as commodities for exchange was upheld by the results. This was clearly a possible response which was resorted to by weaker coal1tion nembers in at least two instances in each casestudy.

I.C.3.b. The proposition that in instances where the more powerful control the resources needed by a potential receptor(s), the weaker unit may try to develop alternative resources aside from the stronger unit was sustained by casestudy evidence. This was a power strategy that was present in each casestudy.

It is conceivable that assertions I.C.3.a. and b. could be listed under "conditions" instead of "situations," since they constitute basically exchange "conditions" of inequality. Another possiblilty would be to reclassify some of the assertions currentIf under "conditions" which are describing situations of interdependency and mutual exchange and categorize them under "sltuations." 
I.D. The I.D. series of seven "analytical questions" will be rated on the same scale as the rest of the material but with the altered meaning of the terms "1dentical" and "opposite" to refer to the degree of continuity between the question and the degree of relerant material in the casestudy. If the question is relerant and useful for analysis, then there is an 1denticalness of the question and the material.

I.D.1.-7. There was considerable case materlal avallable for all of the analytical questicns. The two questions which had the least data were 3 ("who exerclsed or attempted to influence whom in each decision issue?") and 6 ("What position did each unit take on each decision issue as compared to the outcome of the decision-making process?") Both of these questions were highly useful analytically when the data was available. The problem was in the occasional lack of casestudy data, not in the analytical. questicns. These questions explicated the data and key decisional and power issues so clearly that it wculd be more productive to have them proceed section I.C. "Exchange Issues" instead of following 1t. This would help clarify the data to be assessed by the "exchange" assertions.

II.A.1. The assertion that the degrees of familiarity with probiems and with solutions are conceivable within a continuum of routine, incremental, and Innovative was supported by the casestudy results. It should be clarified that in this assertion the familiarity of the coalition as an entity is what is being measured, not that of each unit member. The application of this 
assertion does require a certain arbitrariness, but it should be done with cautious rationality.

II.A.2. The assertion that problem situation and solution types are usually Identical was slightly supported by the data. In fact, one case Indicates the opposite; while one case indicate the two variables as identical; and yet two cases are ambiguous. A broader sampling may be necessary to further assess the basis for this discrepancy, but it does appear that a more viable assertion might be "while problem situation and solution types may be ldentical, any combination of types can, and frequently does occur."

II.A.3. The assertion that the variable of informational adequacy was useful as related to the sufficiency of understanding of the demands of the problem situation and of the consequences of the problem solution for what they are: innovative, incremental, or routine had mixed support from the casestudy mater1a1. It was very helpful in the cases where obvious inadequacy existed in problem situations and solutions, and the concept helped clarify the case material. In the cases where no lack of information was apparent, the notion seemed to be of no obvlous value. Actually, its value cculd have been that it specified that the information was adequate. This notion does seem to have analytical value.

II.B.1. The assertion that in application to interorganizational coalitions, it is probable that nearly all problem situations and solutions w1ll be innovatively oriented was overwhelmingly un- 
substantiated by the casestudy data. Out of all of the 37 casestudy decision issues classified, only 8 were consistent with the assertion and 7 of these occurred quite early in coalitional operations. This indicates either a faulty application of the assertion, or inadequate and/or inaccurate casestudy material, or an invalid assertion. These concepts tend to be difficult to apply, but the extensiveness of the data's refutation of the assertion as it is stated makes its validity highly questionable im the least. The assertion seems to have falled to account for the predominance of routinized and adaptive dimensions of a coalition's decision 1ssues. A coalition appears to quickly acquire its own modus operandi and purpose as an organization.

II.B.2. The proposition that once basic ground rules are estabilshed and the coalition gains experience, the other orlentations (1ncremental and routine) will become operative was slightly supported by the analysis of the data. The results were "slight" in their confirmation of the assertion; because, while the extreme-Iy early decision(s) of each coalition was innovative-innovative," very few Innovative-innovative instances took place and an insignificant number of routine decisions. The latter is, however, probably the result of the analytical model' $s$ bias of assessing "main decisicns" which tends to preclude routine problems. In addition the case materlal tended to be cursory, which falled to relate minor detalls and routine occurrences. The assertion, subsequently, seems to have viablilty and relevance, but additional analysis of it would be helpful. 
II.B.3. The proposition that certain procedures or phases in: dec1sion-making seem to be relatively consistent in most situations: where rationality is regarded as significant by the particlpants was relatively well substantiated by the data. The relativeness of the: substantiation is the result of the fact that those cases in which particlpants valued rationality did demonstrate consistent phases or steps in decision-making. At the same time, those two cases which indicated low participant valuation of rationality could indicate nothing about the validity of an assertion which only assesses instances of a rational process.

II.B.3.a. The assertion that the applicability of the rational model is probably relative to the degree of cooperation of conflict of goals and interests of the units comprising the interorganizational coalition was supported by the casestudy findings. The evidence indicates that interest and goal cooperation and conflict are conditions, but not the causes, of whether rational decision-making takes place or not. This is indicated by, one casestudy which was a predominantly consensus operation, but.which In several instances used irrational decision-making procedures. While cooperation existed it did not necessitate or cause rationality, it just made it possible. Interest and goal conflict tend to make the rational decision-making phases impossible, because coalition alternatives are viewed with minimal objectivity. This does notimean, however, that an individual unit's goals are not rational in terms of its self interest. In a rational sense. II.B.4. The assertion that in coslitions, strong unit biases should be expected to be operative in the decision-making phases was extremely well supported in the casestudy results. This is 
not. Inconsistent with the findings related to assertion II.B.3.a., because units can be seeking to protect and promote their domain and bias, but can achieve this in a rational process under conditions of cooperation and interdependency.

II.B.5. The proposition that 1ssue and interest agreement or disagreement among units are both compatible with the formation of a coalition was only "slightly" confirmed by the casestudy data. The problem is primarily; that, while both interest. and issue agreement and disagreement are compatible with coalition formation, serious and fundamental disagreement may not be compatible with the maintenance of the coalition. This ambiguity needs to be clarifled and can be with the addition of the assertion:(II.B.5.a.): "fundamental and serious issue and interest. disagreement tends to be incompatible with the maintenance and continued existence of coalitional membership, especlally if it. is in conflict with the member's goals."

Cummulative Mean Scores - Indicate a significant degree of conststency and ldentity between the analytical model and the casestudy findings.

\section{Summary of Recommended}

Analytical Model Modifications

These recommendations are the result of the casestudy findings and comments upon them, which ldentified several model propositions that were deficient in whole or in part and several instances of needed model restructuring. Since the criticisms were listed in the above comments, only the affected assertions 
w11l be given here with their suggested alterations:

I.B.1.a.2) It appears that the autonomy, w1thin the coalition, of coalition members is lessened relative to the coalition's control of resources and sophistication of internal organization.

I.B.1.b.1) It is probable that in certain instances the extracoalitional relations of the coalition as an entity could signfficanty influence its decisions and actions.

I.B.1.d. While a single formal leader in a coalition indicates an Imbalance of formal power within the coalition, several formal leaders in a coalition indicates a balance of formal power within the coalition.

I.B.1.e. While a single informal leader in a coalition indicates an imbalance of informal power within the coalition, several informal leaders in a coalition indicates a balance of formal power within the coalition.

I.B.1.f. While a single leader (formally and informally) in a coalition indicates an imbalance of overall power within the coalition, several leaders (formally and/or informaliy) in a coalition Indicates a balance of overall power within the coalition.

I.B.2.a. Formal coalltional roles, if they are established, usually carry little real power, internally.

I.B.2.a.1) When formal coalitional roles do carry real power, it usually is the consequence of those in formal leadership also concurrently controlling significant informal power resources. 
I.D.1-7. Anslytical Questions to 80 before I.C. Exchange Issues.

I.C.1.c. Unit goals and unit cooperativeness -

I.C.1.c.1) If a unit's goals are consistent with the coalition's, and the unit is highly committed to its interest in those gosis, the hlgher the level of cooperation of that member.

I.C.1.c.2) If a unit's goals are contrary to the coalition's and the unit is highly committed to its interest in those goals, the lower the level of cooperation of that member (disruptive, conflictual behavior is quite possible).

I.C.3.a. and b. should be placed in between assertions I.C.1.d. and $\theta$. and the category "S1tuations" under "Exchange Issues" should be eliminated under I.C.3. and the section I.C.1. should read: "Conditions and Situations."

II.A.1. Degrees of coalitional familiarity with problem situations and solutions (or decisions) are concelvable within a continuum of routine, incremental, and innovative.

II.A.2. While problem situation and solution types may prequently: be identical, any combination of types also can, and frequently does, occur.

II.B.1. Among the early main decisions of a coalition, there usuaily are one or more problem situations and solutions which are both innovatively oriented (Innovative-innovative).

II.B.3.b. While cooperation does not necessitate raticnal dec1sion-making, it tends to be sltuationally conducive for its occur- 
rence; while conflict tends to have the opposite result.

II.B.5.a. Fundamental and seriously overt issue and interest disagreement tends to be inccmpatible with the maintenance and continuad existence of coalitional membership, especially: if it is in conflict with the member's goals.

\section{CONCLUSION}

The development and testing of these declsion-making power and process assertions to the four casestudies helped to focus the theoretically analytical onto the empirically testable. The: result of this was a general substantiation of the proposed assertions with the specific revision of certain of the propositions. The model did provide a useful scheme for clarifying and explicating the decision-making of the coalitions. A broader application of the model to additional casestudies could further the testing and revising of it in order to develop a more reliable instrument for assessment.

The study sought to expand the body of knowledge of interorganizational behavior in the specific area of coalitional deci810n-making. This study has advanced that understanding and helped relate the theories and methods of soclal sclence to 1 t. The purpose of the study was not to establish "the analytical model but to help initiate the inquiry into the field of interorganizational dec1sion-making behavior with a set of assertions that might help to assess that phenomenon and to test those assertions. Th1s was done and, revisions, were made in what. appeared to be a relatively salient analytical model. Additional testing 
and the development of different and alternate assertions and models would further help analyze the little studied and understood context and content of interorganizational behavior. Toward this goal, a further review and assessment of the literature Eiven in Chapter 1 , and additional relevant writings, would assist in providing subsequent analytical modifications and alternatives to the model developed in this study.. 
Whe whole concept of a practicum emphasizes the value of the learning. process to the student in: doing research. Because "practice learning" was. so central to th1s project, it would be remise not to assess what was learned from the experience. Th1s concern will be viewed from three perspectives: (1) what the researcher learned, (2) what others might do in light of this," and (3) what the professeion of Social Work might. leam.

\section{What the researcher learned.}

Perhaps the most significant learning of the whole process was the realization of the limitations of any method of research. There tends to be a myth about the irrefutability of the scientific method. From this ex-perience it is clear that this was not the case here. This is not completely the fault of scientific analysis, it is also because of the limitations of any single application of this method. The constructive aspect of this realization is that frequently many of the flaws in a research method and design can be minimized once its ilmitaticns are recognized.

With specific reference to this research project, there are several weaknesses in the model which later became apparent. These weaknesses are significant noti only for their impact on the study but also upor. what the researcher leurned about social science research.

One of these realizations concerned how the research was initiated. The method of identifying key concepts and variables for the analytical model was through a review of pertinent material in the literature. This focus was maintained until the model was fully formulated before the casestudies were referred to by the researcher. This resulted in a conceptual distance between the model and the data. This was especially evident in two areas: (1) unclear concepts, and (2) too narrow a focus upon the model. With respect to point (1), there were several concepts which were 
elther insufficiently delineated or were too broad or too narrow in: meaning and application. Rationality was one such term. It was meant. to refer to "objectivity" in: an impartial assessment of goals and alternatives. This, however, referred to the coalition as a whole and did not account for the variable of rationality which describes the behavior of go8I and alternative assessment and cholce by individual, member units, according. to their best self interest, which could be considered quite Irrational. from the view point of the total coalition yet quite rational. from the member's perspective. Another difficulty with rationality also stems from the peculiar strategy which a coalition might pursue. Cooperation: tends to appear to be more rational, while conflict tends to appear. to be more random and unplanned, yet both can be equally as rational im pursuit of a coalitional goal. This is particulariy evident in the "BIack Coalition" casestudy, which appeared highly. Irrational in many of its: subgoal decisions (community school, bojcott, etc.): but which was rather successful in: attaining its basic goals (changes and more influence in the school system and greater unification of the black community).

Another Inadequately developed parti of the conceptual structure of the model concerned the notions of conflict and cooperation. These terms. were used to refer to the internal operations of the coalition among its: own member units. of equal significance, but left undeveloped, were these same concepts as applied to the strategy of the coalition as a whole toward its external target, and the significance of this, in turn, upon: the internal operations of the coalition. Even with respect to intermal dynamies, what appeared to be cooperation could easily have been a situation of conflict. An example is the "Child Adrocacy" case whicit had elements of cooperation, but which was also characterized by consider- 
able conflict of interests and goals, bute which also required operatiom In order to attain the goal of acquiring project funds.

Arother varlable which was defined and analyzed too narrowly was. extermel resources. It was accounted for with respect to influencing the relative position of strength of members within the coalition, buti a unit's belonging to the coalition was not seen; : in turn, as being used by members: for the purpose of increasing their external strength. This awareness could have given a different interpretation to some of the members' coalitional behavior - especially tho less significant members.

The fallure to more broadly apply some of these variables: 1s: also related to point (2): too narrow a focus upon the model. Th1s resulted: In an attempt to make the data fit the model, when frequentily it was of a different or broader meaning. As a result, some of these variables (e.g. conflict, coalition membershlp for extermal gain, rationality, etc.) vere: ignored. The model, from the theoretical views upon which it was constructed, was blased toward more of a strictly rational, consensus perspective, lgnoring conflict theory and analysis. Th1s sticking to the model resulted in a too limited data analysis and, therefore ilmited what was learned for "exploratory" purposes.

This all polnts toward the need for the development and use of a broader and more flexible model. If the researcher had used this approach, his learning would have been considerably greater and probably more productive.

\section{What others might do in light of this.}

If anjone were to undertake a study of the same topic area or were to use a similar design and method of research, it would be helpful to correct, or at least avold, some of the problems that resulted in this study. 
Ir order to compensate for the limitations of developing an analyticel model from the literature, it would greatly lessen the conceptual distance between that model and the data, if the researcher were to protest that model. This should be done before the model is finalized and applied to material similar to that. which will be assessed in the research. Realistic modifications can then be made in the concepts and theoretical framework of the model before fully undertaking the study. Thls would help to develop a more adequate set of concepts. However, to more fully correct this weakness, it: would be helpful to retain a position of theoretical flexibility while gathering and analyzing the data. This would also respond to the problem of utilizing a model too narrowly. This could also be remedied with the initial use of a model which was more comprehensive. In this instance, a model which could account for both cooperation and conflict would have allowed greater analytical flexibility. ' It would also be more productive if a researcher were to concentrate on what does not flt the model and why., rather than forcing the data to fiti.

Some of the problems of this study could have been minimized, if a more concise and internally and theoretically consistent model had been ut1lized. This would have allowed for greater concentration on the more significant variables and possible alternatives to them.

\section{What the profession of Soclal Work might learn.}

As was mentioned in the preface to this study, coalitional bohavior is a common but little understood phenomenon. Coalitions are also frequently utilized in the social work, community organization, miliou. This is clearly evident when considering the four casestudies in this project. Each one involved sociel welfare issues and actors. It seems obvious 
that any practice skills, as well as theoretical knowledge, which could be extracted from this study would be of use to social workers in coalltional situations. This, however, was not the central purpose of this study and will mostly be left to inference or to further analysis. There are certain general points, however, which should be commented upon in order to avold being negligent.

Probably the most important. point to be learned by the social worker from this study is that he or she needs to be aware of the interorganizational fleld in order to best promote his goals and interests withIn coalitions. The data emphasized the significance of self interest in: these coalitions. Social workers tend to recede from situations of manipulation, conflict, or anything that fails to uphold the value dominance of altruism. However, in coalitional behavior, it is crucial to be aware of the goals, "hldden agendas," and resource manipulations that usually characterize the interorganizational fleld. Not to engage ir such calculation of the tactics of others, and the use of the same, is tantamount to outright concession of one's own interest.

The next issue is whether in fact the interest of social workers merits the above type tactics and behavior. For within the coalitional fleld, being aware of the vulnerability of others is not so much to remedy them (casework therapy) as $i t$ is to manipulate the same for one's own interests and goals. This: is not.solely. without altruistic or humanistic value, in that it will be up to the moral discretion of the individual involved. Furthernore, the welfare of the public, especially the poor, is often the least considered interest in many policy and program decisions, and social workers can assume their role as an effective advocate for these people only if calculated and realistic coalitional practices are employed. From the findings of the study, this would in- 
clude deliberate assessment and use of tactics dealing with such things as reoogmining each member's domain and the implications of that to this particular coalition and 1 ts goal and possible resources. It would be important to know the external resources and relationshlps of other members, Including other ties among member units and the importance of their membership in the coalition to their interests external to the coalition. Who is more influential on which issues and where to most effectively use one's own influence is a key problem. It is also cruclal to know. what other units value for exchange purposes. The role and use of conflict and cooperation by others and oneself in terms of when they are appropriate and what they mean when they occur are of considerable value to the practitioner, as well as are other numerous aspects of coalitional behavior which have been examined by this and other studies.

It is hoped that this study will stimulate further exploration and analjsis of interorganizational coalitions. It is also hoped that it has ralsed as many, if not more, questions and issues as it has attemptea to consider and answer. What has been learned, as mentioned above, should not be overlooked in Iuture inquiries and practice. 


\section{FOOTNOTES}

1 Terry N. Clark, "The Concept of Power," Community Structure and Dec1sion-Kaking, ed. Terry N. Clark (San Francisco: 1968), pp. 73-74.

2Ib1d., pp. 74-78.

3íide., pp. $78-80$.

4jdward Banfleld, Politlcal Influence (New York: 1961), p.3.

5Ib1d., pp. 4-6.

6Ib1d., pp. 318-322.

Thobert A. Dahl, Nodern Polltical Analysis (Inglewood Cliffs: 1963$),$ p. . 40 .

8Ib1d., pp. 50-51.

9ilelson W. Polsby, Ccmmunity Power and Polltical theory (New Haven: 1965), , p. 5:

10 Ib1d., p. 123.

11 Ib1d., pp. 124-136.

12 Ib1d., p. 137.

13Norton E. Long, "The Administrative Organization as a Polltical system," Concepts and Issues in Adminlstrative Behavior, ed. Sidney Mallick (Englewood Cliffs: 1962), pp. 113115.

14 Yehezkel Drcr, Public Policymaking Process (San Francisco: 1968), pp. 78-79.

15 Ibia., p. 80.

161bia., pp. 81-82.

17 Robert. V. Presthus, "Authority in Crganizations," Concepts and Issues in Admiristrative Behavior, ed. Sidney Ma1Iick (Englewood Cliffs: 1962), pp. 135-136.

18 Ibid., p. 124.

${ }^{19}$ Charles E. Lindblom, The Policy-Making Process (New York: 1967), pp. 37-42.

${ }^{20}$ Ib1d., pp. 93-99. 
21 William J. Re1d, "Inter-organizational Coordination ir: Social ielfare," Readings in Community Crganization Practice, ed. Ralph M. Kramer and Harry Specht (Enelewood Cliffs: 1969), pp. 178-181.

22 Mayer N. Zald, "Organizations as Pollties," Readings in: Community Organization Practice, ed. Ralph Mr. Kramer and Harry. Specht (Englewood Cliffs: 1969), pp. 152-153.

23Mager N. Zald, "Political Economy," Power in Organizations, ed. Mayer N. Zald (Nashville: 1970), pp. 231-232.

24pror, op. c1t., pp. 188-191.

25Ronald L. Nuttall, Erwin K. Scheuch, and Chad Gordon, "On the Structure of Influence," Community Structure and DecisionYaking, ed. Terry N. Clark (San Francisco: 1968), pp. 349-350.

26Ibid., pp. 352-356.

27 Ib1d., pp. 358-359.

28 Ib1d., pp. 360-364.

29.1b1d., pp. 364-365.

30 Charles R. Adrian and. Charles Press, "Decision Costs in Coalition Formation," The American Political Solence Roviow, IXII, No. 2 (June, 1968), pp. 556-557..

31 Ib1a., p. 562 .

32clark op. cit., pp. 49-52.

33 Ibid., pp. 53-54.

34 Ibid., pp. 62-63.

35Re1d, op. c1t., pp. 182-184.

36peter M. Blau, Exchange and Power in Social Life (New York: 1964), p. .124.

37 David Braybrooke and Charles $\mathrm{E}$. IIndblom, A Strategy of Decision (New York: 1967), p. 66.

38 William Gore, "Dec1sion-Making Research: Some Prospects and Limitations," Concepts and Issues in Administrative Behav10r, ed. Sidney Malilck (Englewood Cliffs: 1962), pp. 52-53.

39 Ibid., pp. 55-58.

40Edward Harvey and Russell Mills, "Patterns of Organization- 
al Adaptation: A Politic Perspective," Power in Organizations, od. Uayer N. Zald (Nashrille, 1970), p. 190.

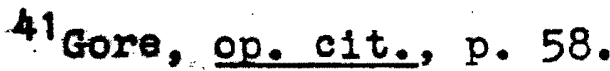

42 Harvey op. c1t., pp. 194-198.

43 Ibza., p. 199.

44ibid., pp. 200-101.

45Orvilie G. Brim, Jr., David C. Glass, et. al., Personal1ty and Decision Processes (Stanford: 1962), pp. 9-io.

46 Terry n. Clark, "The Concept of Power," Community Structure and Dec1sion-Making, ed. Terry N. Clark (san Francisco: 1968), p. 65 .

47Herbert A. Simon, Administrative Behavior (New York: 1961), pp. 65-66.

48 Ib1d., pp. 66-73.

49 Ib1d., pp. 73-74.

50Ibid., pp. 75-76. 


\section{BIBLICGRAPEY}

Banfleld, Edward C. Political Influence. New York: The Free Press, 1961 .

Blau, Peter M. Exchange and Fower in Soclal Life. New York: John: wiley and Sons, Inc., 1964.

Braybrooke, David and Charles E. Lindblom, A Strategy of Dec1sion. New York: The Free Press, 1967.

Brim, Crville G., Jr., David C. Glass, et. al. Personality and Decision Processes. Stanford: Stanford University Press, 1962.

Clark, Terry N. "The Concept of Power." Commun1ty Structure and Decision-Making. ed. Terry N. Clark. San Franc1sco: ChandIer Publishing Company, 1968.

Dahl, Robert A. Modern Polltical Anelysis. Englewood Cliffs: Prentice-Hail, Inc., 1963.

Davis, Morris and Marvin G. Welnbaum. Metropolitan Decision Processes. Chicago: Rand McNally and Company, 1969.

Dror, Yehezkel. Public Pollcymaking Reexamlned. San Francisco: Chandler Publishing Company, 1968.

Gore, Wliliam. "Dec1sion-Making Research: Some Prospects and Limitations." Concepts and Issues in Administrative Behavior. ed. Sidney Malilck. Englewood Cliffs, 1962.

Harrey, Edward and Russeli Mills. "Patterns of Organizational Adaptation." Power in Organizations. ed. Mayer N. Zald. Nashrille: Vanderbilt University Press, 1970.

Lindblom, Charles E. The Pollcy-Making Process. Englewood Cliffs:: Prentice-Hall, Inc., 1968.

Long,, Norton E., "The Administrative Crganization as a Polltical system." Concepts and Issues in Administrative Behavior.. ed.. Sidney Mallick. Englewood Cliffs: Prentice-Hall, Ine., 1962.

Nuttall, Ronald I.,., Erwin K. Scheuch, and Chad Gordon. "On the Structure of Influence." Community Structure and Dec1sionMaking. ed. Terry N. Clark. San Francisca: Chandler Pub118hing Compang, 1968.

Polsby, Nelson $w$. Community Power and Political Theory. New Haven: Yale University Press, 1965.

Presthus, Robert V. "Authority in Organizations." Concepts and Issues in Administrative Behavior. ed. Sidney Mailick. Englewood Cliffs: Prentice-Hall, Inc., 1962. 
Re1d, William J. "Inter-organizational Coordination in Soclal Welfare." Readings in Community Crganization Practice. $\epsilon$ d. Ralph M. Kramer and Harry Specht. Englewood Cliffs: Prentice-Hall, Inc., 1969.

Simon, Herbert A. Administrative Behavior. New York: The Macmillan Company, 1961.

Warren, Roland L. Truth, Love, and Social Change. Chlcago: Rand MeNally and Company, .1971.

Zald, Mayer N. "Organizations a.s Polities." Readings in Communlty: Organization Practice. ed. Ralph M. Kramer and Harry Specht.. Englewood Cllffs: Prentice-Hall, Inc., 1969.

Zald, Mayer N. "Political Economy." Power in Organizations. ed. Mayer N. Zald. Nashville: Vanderbilt University Press, 1970.

\section{PERICDICALS}

Adrian, Charles R. and Charles Press. "Decision Costs in Coal1tion Formation." The American Polltical Science Review.

IXII, N. 2. June, 1968, pp. 556-563.

\section{UNPUBLISHED PAFERS}

Warren, Roland L. "The Concerting of Decisions as a Variable in organizational. Interaction." (original version). 